Article

\title{
Winter Wheat Nitrogen Estimation Based on Ground-Level and UAV-Mounted Sensors
}

\author{
Xiaoyu Song ${ }^{1,2}$, Guijun Yang ${ }^{1,2}$, Xingang $X u^{1,2}$, Dongyan Zhang ${ }^{3, *} \mathbb{C}$, Chenghai Yang ${ }^{4}\left(\mathbb{D}\right.$ and Haikuan Feng ${ }^{5}$ \\ 1 Information Technology Research Center, Beijing Academy of Agriculture and Forestry Sciences, \\ Beijing 100097, China; Songxy@nercita.org.cn (X.S.); Yanggj@nercita.org.cn (G.Y.); \\ Xuxg@nercita.org.cn (X.X.) \\ 2 Key Laboratory of Quantitative Remote Sensing in Agriculture of Ministry of Agriculture, \\ Beijing 100097, China \\ 3 Anhui Engineering Laboratory of Agro-Ecological Big Data, Anhui University, Hefei 230601, China \\ 4 Aerial Application Technology Research Unit, USDA-Agricultural Research Service, \\ College Station, TX 77845, USA; chenghai.yang@usda.gov \\ 5 National Engineering Research Center for Information Technology in Agriculture, Beijing 100097, China; \\ Fenghk@nercita.org.cn \\ * Correspondence: Zhangdy@ahu.edu.cn
}

Citation: Song, X.; Yang, G.; Xu, X.; Zhang, D.; Yang, C.; Feng, H. Winter Wheat Nitrogen Estimation Based on Ground-Level and UAV-Mounted Sensors. Sensors 2022, 22, 549 . https://doi.org/10.3390/ s22020549

Academic Editors: Christopher C. Stewart and Huiping Tsai

Received: 13 December 2021

Accepted: 7 January 2022

Published: 11 January 2022

Publisher's Note: MDPI stays neutral with regard to jurisdictional claims in published maps and institutional affiliations.

Copyright: (C) 2022 by the authors. Licensee MDPI, Basel, Switzerland. This article is an open access article distributed under the terms and conditions of the Creative Commons Attribution (CC BY) license (https:// creativecommons.org/licenses/by/ $4.0 /)$.

\begin{abstract}
A better understanding of wheat nitrogen status is important for improving $\mathrm{N}$ fertilizer management in precision farming. In this study, four different sensors were evaluated for their ability to estimate winter wheat nitrogen. A Gaussian process regression (GPR) method with the sequential backward feature removal (SBBR) routine was used to identify the best combinations of vegetation indices (VIs) sensitive to wheat $\mathrm{N}$ indicators for different sensors. Wheat leaf $\mathrm{N}$ concentration (LNC), plant $\mathrm{N}$ concentration (PNC), and the nutrition index (NNI) were estimated by the VIs through parametric regression (PR), multivariable linear regression (MLR), and Gaussian process regression (GPR). The study results reveal that the optical fluorescence sensor provides more accurate estimates of winter wheat $\mathrm{N}$ status at a low-canopy coverage condition. The Dualex Nitrogen Balance Index (NBI) is the best leaf-level indicator for wheat LNC, PNC and NNI at the early wheat growth stage. At the early growth stage, Multiplex indices are the best canopy-level indicators for LNC, PNC, and NNI. At the late growth stage, ASD VIs provide accurate estimates for wheat $\mathrm{N}$ indicators. This study also reveals that the GPR with SBBR analysis method provides more accurate estimates of winter wheat LNC, PNC, and NNI, with the best VI combinations for these sensors across the different winter wheat growth stages, compared with the MLR and PR methods.
\end{abstract}

Keywords: leaf nitrogen concentration; plant nitrogen content; nitrogen nutrition index; Gaussian process regression

\section{Introduction}

Nitrogen $(\mathrm{N})$ is a crucial nutrient required for crop growth and grain formation. Agricultural managers can regulate $\mathrm{N}$ management at suitable rates and opportune moments based on the crop's $\mathrm{N}$ requirements. As an essential scatheless and real-time technique, remote sensing technologies have been proved valuable for crop $\mathrm{N}$ status evaluation [1-6].

Much meaningful progress in sensor technology for evaluation of plant $\mathrm{N}$ status has been achieved in recent years. Leaf sensors, such as chlorophyll meters [7-9] and Dualex sensors [10], have been widely used to measure crop N status. These leaf clip sensors show a stable relation with plant $\mathrm{N}$ due to their direct contact with the plant. However, there are also some restrictions on these sensors because plant leaf water content, leaf structure, or other nutrient deficiencies may also easily influence the sensor readings [11]. Some studies indicate that measurement of polyphenol concentrations in the leaf is a new method to overcome such barriers [12]. The ratio of chlorophyll to polyphenol is more stable 
than the leaf chlorophyll distribution $[11,13]$. At the canopy level, the spectral features of chlorophyll from the visible to near-infrared bands are used as indicators of crop N [14-16]. The Multiplex 3 portable sensor has also been widely used for plant $\mathrm{N}$ diagnosis in recent years, and it can detect plant chlorophyll and flavonol compounds simultaneously through the chlorophyll fluorescence method [17]. As a new exploration of the low-altitude remote sensing method, unmanned aerial vehicle (UAV)-based sensing has been widely used in different fields recently due to its flexibility, affordability, and applicability for large-scale monitoring compared to handheld active sensing $[18,19]$. Digital color images acquired by UAV or airplane-mounted sensors have also proven to be a feasible way to estimate canopy variables such as leaf chlorophyll content [20], nitrogen status [21], wheat senescence [22], and vegetation cover [23] in a large area [24]. In general, rapid, precise, and non-destructive acquisition of $\mathrm{N}$ information has become an essential technique for crop nutrition and growth diagnosis $[5,25]$, which helps dynamic regulations of $\mathrm{N}$ fertilizer use [26].

Previous studies attempted to retrieve $\mathrm{N}$ via a radiative transfer model. As an example, Jacquemoud et al. attempted to incorporate $\mathrm{N}$ into the PROSPECT model, but this approach was abandoned because of inconsistencies in $\mathrm{N}$ retrieval through model inversion [27]. More efforts have been directed at estimating crop $\mathrm{N}$ status using empirical methods based on observed reflectance to measured vegetation characteristics [28,29]. Many practical regression techniques using hyperspectral bands, vegetation indices (VIs), and different types of sensor data have been proved influential in plant $\mathrm{N}$ estimation $[21,28,29]$. Parametric regression (PR) methods based on band information or VIs of broadband satellite sensors are probably the oldest and largest group of variable estimation approaches [30]. VIs enhance spectral features sensitive to a vegetation property while reducing disturbances by combining some spectral bands [31,32]. The major advantage of VIs is their intrinsic simplicity. However, the selection of an optimal subset of hyperspectral bands or best VIs sensitive to plant $\mathrm{N}$ encounters both numerical and computational difficulties $[33,34]$. Multivariable linear regression (MLR) methods are attractive because of their fast performance in coping with spectroscopic data and their typical reliance on the estimation of covariances [30]. Miphokasap et al. demonstrated that the model developed by MLR led to a higher correlation coefficient and lower errors than model applications based on narrowband VIs in estimating canopy nitrogen [30,35]. In recent decades, a variety of non-linear, non-parametric methods have been developed, going beyond linear regression or linear transformation techniques. These methods, also referred to as machine learning regression algorithms, apply non-linear transformations [30]. Gaussian process regression (GPR) applied to spectroscopic and hyperspectral data started more recently, such as airborne HyMap mapping of leaf chlorophyll content [36] and spaceborne CHRIS mapping of leaf chlorophyll content, LAI, and fractional vegetation content [37]. The GPR method is deemed to be one of the most exciting machine learning regression algorithms, which can provide a full conditional statistic for the predicted variable [38,39]. GPR with the sequential backward feature removal (SBBR) routine proposed by Verrelst et al. leads to the identification of the most sensitive vegetation index for the crop nitrogen variable [34].

Nevertheless, when this technique is applied in studies with spectral data from different sensors, results on the best VIs or combinations and their performance on crop nitrogen diagnosis have rarely been reported. Therefore, in this study, we propose assessing the performance of different sensors for winter wheat N status estimation through PR, MLR, and GPR analyses. To determine which spectral features could sufficiently estimate crop $\mathrm{N}$ status indicators, we considered one leaf $\mathrm{N}$ status indicator (i.e., the leaf $\mathrm{N}$ concentration (LNC)), one plant $\mathrm{N}$ status indicator (i.e., the $\mathrm{N}$ plant concentration (PNC)), and one relative plant $\mathrm{N}$ indicator (i.e., the nutrition index (NNI)), which is calculated as the ratio of the measured $\mathrm{N}$ concentration and the critical $\mathrm{N}$ concentration. In this study, we also performed sensitivity analysis on the wheat $\mathrm{N}$ indicators for different sensors through the PR, MLR, and GPR methods. The main objectives of this study were to: (1) evaluate the ability of four different proximal and UAV-mounted sensors for winter wheat $\mathrm{N}$ status estimation; (2) identify the optimal VIs and VI combinations derived from the sensors for 
accurate winter wheat $\mathrm{N}$ status estimation; and (3) determine whether GPR models based on the combination of VIs could further improve the estimation accuracy.

\section{Materials and Methods}

\subsection{Experimental Design}

This study was carried out at the National Experimental Station for Precision Agriculture in the Changping District of Beijing, China $\left(40^{\circ} 10.6^{\prime} \mathrm{N}, 116^{\circ} 26.3^{\prime} \mathrm{E}\right.$; Figure 1$)$. The area of the study field was about 0.80 ha. Winter wheat was sown on 4 October 2013, in $15 \mathrm{~cm}$-wide rows. The variety of wheat was Jindong 22. A total of 8 different nitrogen fertilizer treatments were assigned to 104 plots in this experiment, each plot measuring $7 \times 7.5 \mathrm{~m}$ (Figure 1 ). There was a $1 \mathrm{~m}$ buffer around each fertilization plot to minimize the interference between different fertilizer treatments. Base fertilizer, including $72 \mathrm{~kg} / \mathrm{ha} \mathrm{N}$, $60 \mathrm{~kg} / \mathrm{ha} \mathrm{P}_{2} \mathrm{O}_{5}$, and $75 \mathrm{~kg} / \mathrm{ha} \mathrm{K}_{2} \mathrm{O}$, was applied to the experiment plots when the wheat was seeded, except for the CK treatments. Topdressing was applied at the wheat jointing stage (16 April, corresponding to Feekes 6), and detailed fertilizer information about the treatments is listed in Table 1.

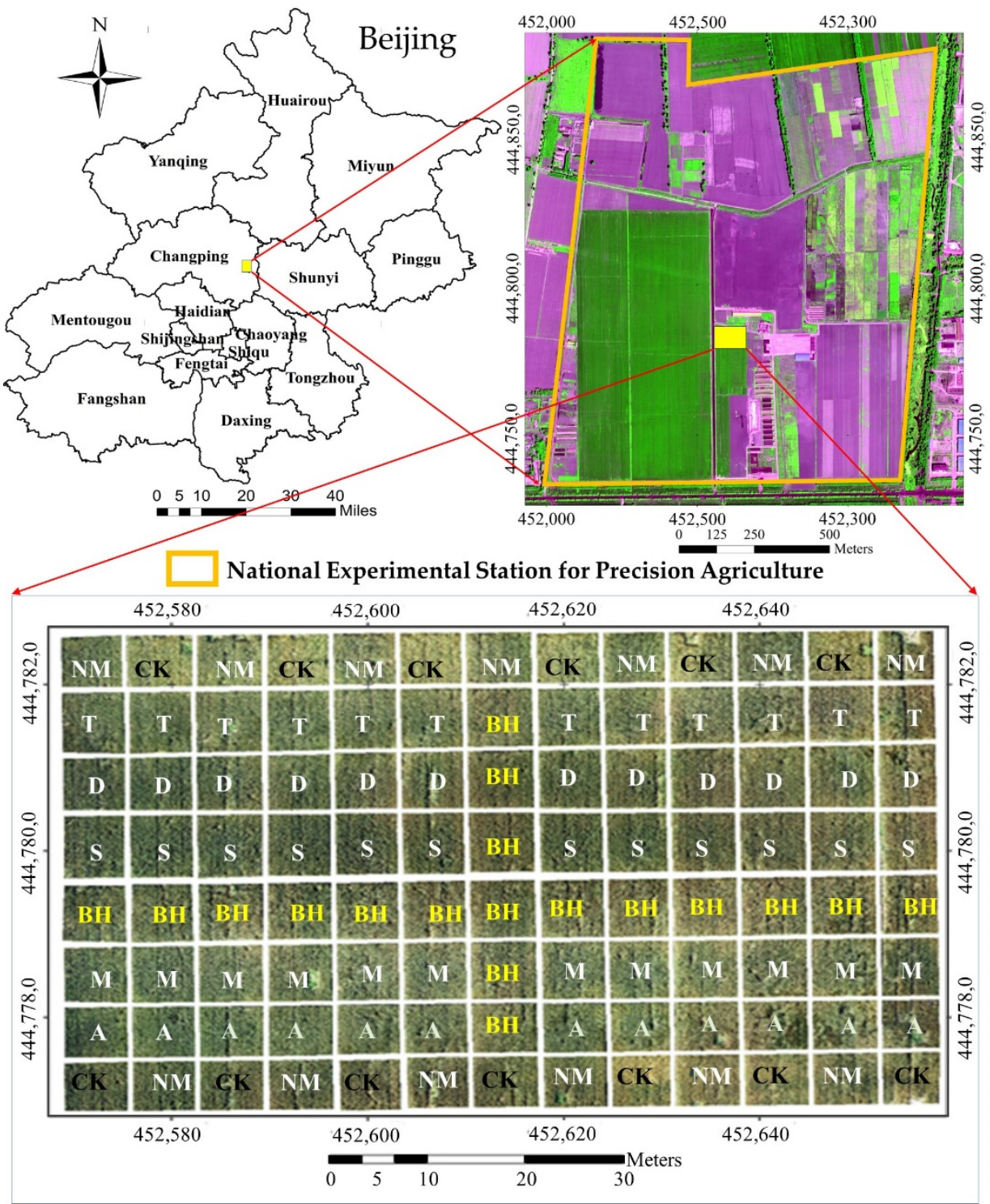

Figure 1. Study area and experimental design. NM treatment: A recommended conventional, uniform 
nitrogen fertilization treatment; $\mathrm{CK}$ treatment: non-nitrogen fertilizer treatment; $\mathrm{BH}$ treatment: excess nitrogen fertilizer treatment (N-rich strip treatment); $\mathrm{S}$ treatment: variable-rate nitrogen treatment with fertilizer rate based on the SPAD value ratio between this treatment and N-rich strip treatment; A treatment: variable-rate nitrogen treatment with fertilizer rate based on the ASD spectroradiometer vegetation index OSAVI value ratio between this treatment and N-rich strip treatment; T treatment: variable-rate nitrogen treatment with fertilizer rate based on the ASD spectroradiometer vegetation index REPLI value ratio between this treatment and N-rich strip treatment; D treatment: variable-rate nitrogen treatment with fertilizer rate based on the Dualex NBI value between this treatment and $\mathrm{N}$-rich strip treatment; and $\mathrm{M}$ treatment: variable-rate nitrogen treatment with fertilizer rate based on the Multiplex NBI_R value ratio between this treatment and N-rich strip treatment.

Table 1. Fertilizer information for different treatments.

\begin{tabular}{|c|c|c|c|c|c|c|c|c|c|}
\hline \multirow{2}{*}{ Treatment } & \multirow{2}{*}{$\begin{array}{c}\text { Plot } \\
\text { Number }\end{array}$} & \multicolumn{2}{|c|}{ Base Fertilizer } & \multicolumn{2}{|c|}{ Topdressing Fertilizer } & \multicolumn{4}{|c|}{ Fertilizer Treatment Rate Statistic } \\
\hline & & Time & N kg/ha & Time & N kg/ha & Mean kg/ha & Min kg/ha & Max kg/ha & $\mathrm{CV} \%$ \\
\hline $\mathrm{BH}$ & 18 & Seed & 72 & Feekes 2, 4 & 51,102 & 225 & 225 & 225 & 0 \\
\hline NM & 13 & Seed & 72 & Feekes 6 & 78 & 150 & 150 & 150 & 0 \\
\hline CK & 13 & Seed & 0 & Feekes 6 & 0 & 0 & 0 & 0 & 0 \\
\hline A & 12 & Seed & 72 & Feekes 6 & 78 & 150 & 147 & 154.1 & 1.78 \\
\hline M & 12 & Seed & 72 & Feekes 6 & 78 & 150 & 138.6 & 162.2 & 5.15 \\
\hline $\mathrm{D}$ & 12 & Seed & 72 & Feekes 6 & 78 & 150 & 141.6 & 160 & 3.04 \\
\hline$S$ & 12 & Seed & 72 & Feekes 6 & 78 & 150 & 144.7 & 154.8 & 1.92 \\
\hline $\mathrm{T}$ & 12 & Seed & 72 & Feekes 6 & 78 & 150 & 131 & 183.1 & 10.25 \\
\hline
\end{tabular}

\subsection{Sensor Data Collection}

The leaf and canopy spectral parameters were measured in a $1 \mathrm{~m}^{2}$ rectangular region within each plot at the wheat raising stage (8 April 2014, corresponding to Feekes 5) and the filling stage (28 May 2014, corresponding to Feekes 11). In this study, we used four different optical instruments to collect wheat spectral data. The Dualex sensor was used to measure wheat leaf spectral parameters. The Multiplex sensor and the ASD field spectrometer were used to collect wheat canopy spectral parameters. A Sony DSC-QX100 digital RGB camera mounted on a DJI S1000 UAV was used to collect wheat images for the experiment fields. Table 2 lists the detailed information on the sensors used in this study.

Table 2. Parameters on sensors used in this study.

\begin{tabular}{|c|c|c|c|c|}
\hline Sensor Information & $\begin{array}{c}\text { Polyphenol and Chlorophyll } \\
\text { Meter }\end{array}$ & $\begin{array}{c}\text { Polyphenol and Chlorophyll } \\
\text { Meter }\end{array}$ & Field Spectrometer & $\begin{array}{c}\text { UAV-Based Digital } \\
\text { Camera }\end{array}$ \\
\hline Sensor Type & Dualex & Multiplex & ASD & RGB Camera \\
\hline Sensor name & Force-A Dualex Scientific & Force-A MULTIPLEX 3 & ASD FieldSpec 4 & Sony DSC-QX100 \\
\hline Target sample & Plant leaves & Plant canopy & Plant canopy & Plant canopy \\
\hline Field of view & - & - & $25^{\circ}$ & $64^{\circ}$ \\
\hline Image size & - & - & - & $3000 \times 4000$ \\
\hline Working height & - & $10 \mathrm{~cm}$ & $1.3 \mathrm{~m}$ & $50 \mathrm{~m}$ \\
\hline Measurement area & $5 \mathrm{~mm}$ in diameter & $10 \mathrm{~cm}$ in diameter & $50 \mathrm{~cm}$ in diameter & Full field \\
\hline Spectral information & $\begin{array}{c}\text { Excitation channels: UV } \\
(357 \mathrm{~nm}) \text { and red }(650 \mathrm{~nm}) \text {. } \\
\text { Detection channels: red and } \\
\text { far-red. }\end{array}$ & $\begin{array}{c}\text { Excitation channels: UV } \\
\text { (375 nm), blue (450 nm), green } \\
\text { (510 nm), and red (630 nm). } \\
\text { Detection channels: yellow, } \\
\text { red, and far-red. }\end{array}$ & $350-2500 \mathrm{~nm}$ & $\mathrm{R}, \mathrm{G}, \mathrm{B}$ \\
\hline $\begin{array}{l}\text { Original spectral } \\
\text { resolution }\end{array}$ & - & - & $\begin{array}{r}3 \mathrm{~nm} @ 700 \mathrm{~nm} ; \\
10 \mathrm{~nm} @ 1400 \mathrm{~nm}\end{array}$ & - \\
\hline $\begin{array}{l}\text { Data spectral } \\
\text { resolution }\end{array}$ & & & $1 \mathrm{~nm}$ & \\
\hline $\begin{array}{l}\text { Image spatial } \\
\text { resolution }\end{array}$ & - & - & - & $2 \mathrm{~cm}$ \\
\hline
\end{tabular}




\subsubsection{Leaf- and Canopy-Level Data Collection}

For each plot, 10 wheat plants were randomly selected for Dualex measurement. The first and second fully expanded leaves of the plants were clipped at the middle location, and the measurement averages represented the Duelax NBI, Chl, and FLAV values of the plot. Multiplex measurements and ASD spectral measurements were performed and repeated 20 times at $10 \mathrm{~cm}$ and $1.3 \mathrm{~m}$ above the wheat canopy, respectively. The measurement averages represented the wheat canopy fluorescence and reflectance values for each plot. A total of 9 Multiplex fluorescence VIs and 28 ASD spectral VIs sensitive to plant N are listed in Table 3.

Table 3. Vegetation indices based on Multiplex 3 and ASD sensors used in this study.

\begin{tabular}{|c|c|c|c|c|}
\hline Sensor & ID & Vegetation Index & Formula & Reference \\
\hline \multirow{9}{*}{ Multiplex } & 1 & SFR_G & FRF_G/RF_G & [17] \\
\hline & 2 & SFR_R & FRF_R/RF_R & [17] \\
\hline & 3 & BRR_FRF & BGF_UV/FRF_UV & [17] \\
\hline & 4 & FER_RUV & FRF_R/FRF_ŪU & [17] \\
\hline & 5 & FER_RG & FRF_R/FRF_G & [17] \\
\hline & 6 & FLĀV & Log(FER_RŪV $)$ & [17] \\
\hline & 7 & ANTH & Log(FER_RG) & [17] \\
\hline & 8 & NBI_G & FRF_UV/RF_G & [17] \\
\hline & 9 & NBI_R & FRF_UV/RF_R & [17] \\
\hline \multirow{28}{*}{ ASD } & 1 & $\mathrm{SR}_{(700,670)}$ & $\left(\mathrm{R}_{700}\right) /\left(\mathrm{R}_{670}\right)$ & [40] \\
\hline & 2 & $\mathrm{SR}_{(418,450)}$ & $\left(\mathrm{R}_{418}\right) /\left(\mathrm{R}_{450}\right)$ & [40] \\
\hline & 3 & VOGa & $\left(\mathrm{R}_{740}\right) /\left(\mathrm{R}_{720}\right)$ & [41] \\
\hline & 4 & $\mathrm{SR}_{(553,537)}$ & $\left(R_{553}\right) /\left(R_{537}\right)$ & [42] \\
\hline & 5 & NDCI & $\left(R_{762}-R_{527}\right) /\left(R_{762}+R_{527}\right)$ & [41] \\
\hline & 6 & NDRE & $\left(R_{790}-R_{720}\right) /\left(R_{790}+R_{720}\right)$ & [43] \\
\hline & 7 & TBI1 & $\left(\mathrm{R}_{434}\right) /\left(\mathrm{R}_{496}+\mathrm{R}_{401}\right)$ & [44] \\
\hline & 8 & $\mathrm{mND}_{705}$ & $\left(R_{750}-R_{705}\right) /\left(R_{750}+R_{705}-2 R_{445}\right)$ & [45] \\
\hline & 9 & NDIopt & $\left(\mathrm{R}_{503}-\mathrm{R}_{483}\right) /\left(\mathrm{R}_{503}+\mathrm{R}_{483}\right)$ & [46] \\
\hline & 10 & TBI2 & $\left(\mathrm{R}_{924}-\mathrm{R}_{703}\right) /\left(\mathrm{R}_{924}-\mathrm{R}_{703}\right)$ & [47] \\
\hline & 11 & $\operatorname{NDVI}_{(670,780}$ & $\left(R_{780}-R_{670}\right) /\left(R_{780}+R_{670}\right)$ & [48] \\
\hline & 12 & RDVI & $\left(\mathrm{R}_{800}-\mathrm{R}_{670}\right) /\left(\mathrm{R}_{800}+\mathrm{R}_{670}\right)^{1 / 2}$ & [49] \\
\hline & 13 & $\mathrm{SR}_{(750,700)}$ & $\left(\mathrm{R}_{750}\right) /\left(\mathrm{R}_{700}\right)$ & [50] \\
\hline & 14 & WI & $\left(\mathrm{R}_{900}\right) /\left(\mathrm{R}_{950}\right)$ & [51] \\
\hline & 15 & NDWI & $\left(R_{860}-R_{1240}\right) /\left(R_{860}+R_{1240}\right)$ & [52] \\
\hline & 16 & NDII & $\left(R_{819}-R_{1600}\right) /\left(R_{819}+R_{1600}\right)$ & [53] \\
\hline & 17 & MCARI & {$\left[\left(R_{700}-R_{670}\right)-0.2\left(R_{700}-R_{550}\right)\right]\left(R_{700} / R_{670}\right)$} & [54] \\
\hline & 18 & TCARI & $3\left[\left(R_{700}-R_{670}\right)-0.2\left(R_{700}-R_{550}\right)\left(R_{700} / R_{670}\right)\right]$ & [54] \\
\hline & 19 & OSAVI & $1.16\left(R_{800}-R_{670}\right) /\left(R_{800}+R_{670}+0.16\right)$ & [55] \\
\hline & 20 & MSAVI & $0.5\left[2 \mathrm{R}_{800}+1-\left(\left(2 \mathrm{R}_{800}+1\right)^{2}-8\left(\mathrm{R}_{800}-\mathrm{R}_{670}\right)\right)^{1 / 2}\right]$ & [56] \\
\hline & 21 & MCARI 1 & $1.2\left[2.5\left(R_{800}-R_{670}\right)-1.3\left(R_{800}-R_{550}\right)\right]$ & [57] \\
\hline & 22 & MCARI 2 & $1.5\left[2.5\left(R_{800}-R_{670}\right)-1.3\left(R_{800}-R_{550}\right)\right] /\left[\left(2 R_{800}+1\right)^{2}-\left(6 R_{800}-5\left(R_{670}\right)^{1 / 2}\right)-0.5\right]^{1 / 2}$ & [57] \\
\hline & 23 & PPR & $\left(\mathrm{R}_{550}-\mathrm{R}_{450}\right) /\left(\mathrm{R}_{550}+\mathrm{R}_{450}\right)$ & [58] \\
\hline & 24 & PVR & $\left(R_{550}-R_{650}\right) /\left(R_{550}+R_{650}\right)$ & [59] \\
\hline & 25 & PRI & $\left(R_{531}-R_{570}\right) /\left(R_{531}+R_{570}\right)$ & {$[60]$} \\
\hline & 26 & REP & $\left.\left.700+40\left[\left(\mathrm{R}_{670}+\mathrm{R}_{780}\right) / 2\right)-\mathrm{R}_{700}\right) /\left(\mathrm{R}_{740}-\mathrm{R}_{700}\right)\right]$ & [61] \\
\hline & 27 & REV & Reflectance value at REP & [62] \\
\hline & 28 & REFD & First deviation of red edge & [62] \\
\hline
\end{tabular}

\subsubsection{UAV-Level Data Collection}

The UAV digital images were obtained at a $50 \mathrm{~m}$ altitude. Pix4Dmapper software (Pix4D Inc., Lausanne, Switzerland) was used for automatic image mosaicking. The original digital number $(\mathrm{DN})$ values of the images were calibrated by the experimental line method (Equation (1)) [63]:

$$
\mathrm{DN}_{\mathrm{i}}=\frac{\mathrm{DN}_{\text {object }}-\mathrm{DN}_{\text {black }}}{\mathrm{DN}_{\text {white }}-\mathrm{DN}_{\text {black }}} \times 255
$$

where $\mathrm{DN}_{\mathrm{i}}$ represents the calibrated $\mathrm{DN}$ value for band $\mathrm{i}$, such as $\mathrm{R}, \mathrm{G}$, and $\mathrm{B} ; \mathrm{DN}_{\text {object }}$ is the original $\mathrm{DN}$ value of the images; and $\mathrm{DN}_{\text {white }}$ and $\mathrm{DN}_{\text {black }}$ are the original $\mathrm{DN}$ values from the white and black panels in the UAV-DN images. Then, the images were resampled to $2 \mathrm{~cm}$ using the nearest neighbor method. An area of interest (AOI) $(2 \times 2 \mathrm{~m})$ located in 
the middle region of each sample plot was delineated on the image to exclude the border effect. A total of 208 winter wheat AOIs (104 AOIs at wheat Feekes stage 5 and 104 AOIs at wheat Feekes stage 11) were clipped for the subsequent analysis. Then, the spectral data from the mix of winter wheat and soil background were extracted, and the VIs were calculated to indicate the winter wheat growth status for each plot. Table 4 lists the RGB image bands and VIs used in this study.

Table 4. Vegetation indices based on digital RGB images.

\begin{tabular}{|c|c|c|c|c|}
\hline ID & Vegetation Index & Full Name & Formula & Reference \\
\hline 1 & $\mathrm{R}$ & DN values for red band & $\mathrm{DN}_{\mathrm{R}} / 255$ & [64] \\
\hline 2 & $\mathrm{G}$ & DN values for green band & $\mathrm{DN}_{\mathrm{G}} / 255$ & [64] \\
\hline 3 & $\mathrm{~B}$ & DN values for blue band & $\mathrm{DN}_{\mathrm{B}} / 255$ & [64] \\
\hline 4 & $\mathrm{r}$ & Chromatic coordinates for red & $R /(R+G+B)$ & [64] \\
\hline 5 & $\mathrm{~g}$ & Chromatic coordinates for green & $G /(R+G+B)$ & [64] \\
\hline 6 & $\mathrm{~b}$ & Chromatic coordinates for blue & $B /(R+G+B)$ & [64] \\
\hline 7 & ExR & Excess red & $1.4 \times \mathrm{r}-\mathrm{b}$ & [65] \\
\hline 8 & ExG & Excess green & $2 g-(r+b)$ & [65] \\
\hline 9 & NDI & $\begin{array}{l}\text { The normalized difference } \\
\text { vegetation index }\end{array}$ & $(b-g) /(b+g)$ & [65] \\
\hline 10 & CVI1 & Color vegetation index 1 & $(\mathrm{r}-\mathrm{g})$ & [65] \\
\hline 11 & CVI2 & Color vegetation index 2 & $(g-b)$ & [65] \\
\hline 12 & CVI3 & Color vegetation index 3 & $(\mathrm{~g}-\mathrm{b}) /(\mathrm{r}-\mathrm{g})$ & {$[65]$} \\
\hline 13 & GRVI & Green-red vegetation index & $(g-r) /(g+r)$ & {$[65]$} \\
\hline 14 & $\mathrm{NPCI}$ & $\begin{array}{l}\text { Normalized pigment chlorophyll } \\
\text { ratio index }\end{array}$ & $(b-r) /(b+r)$ & {$[66]$} \\
\hline
\end{tabular}

\subsection{Plant Sampling Data Collection}

We collected the plant samples as soon as the sensors' measurements were completed. In this study, plants from an area of $0.12 \mathrm{~m}^{2}$ (two rows and $40 \mathrm{~cm}$ wide) near the spectral measurement plot were collected and sent to the laboratory for analysis. The vegetative organs (leaves, stems, and ears) were then divided and dried in the oven at $80^{\circ} \mathrm{C}$ for $24 \mathrm{~h}$. The biomass $\left(\mathrm{g} / \mathrm{m}^{2}\right)$ for wheat leaves (leaf biomass, LB), stems (stem biomass, SB), and ears (ear biomass, EB) per unit area was calculated based on the measured planting density and the dry weight of the samples. The leaf nitrogen concentration (LNC \% ( $\left.\mathrm{g} \mathrm{N} 100 \mathrm{~g}^{-1} \mathrm{DM}\right)$ ), stem nitrogen concentration (SNC \% (g N $\left.100 \mathrm{~g}^{-1} \mathrm{DM}\right)$ ), and ear nitrogen concentration (ENC \% (g N $\left.100 \mathrm{~g}^{-1} \mathrm{DM}\right)$ ) were then determined using the standard Kjeldahl method [67]. Plant $\mathrm{N}$ accumulation (PNA, $\mathrm{kg} / \mathrm{ha}$ ) was the sum of leaf, stem, and ear $\mathrm{N}$ accumulation (Equation (2)). Wheat plant $\mathrm{N}$ content (PNC \%) was determined by PNA (kg/ha) divided by the plant biomass (kg/ha) (Equation (3)) [68].

$$
\begin{gathered}
\operatorname{PNA}(\mathrm{kg} / \mathrm{ha})=(\mathrm{LB} \times \mathrm{LNC})+(\mathrm{SB} \times \mathrm{SNC})+(\mathrm{EB} \times \mathrm{ENC}) \\
\operatorname{PNC}(\%)=\mathrm{PNA} /(\mathrm{LB}+\mathrm{SB}+\mathrm{EB})
\end{gathered}
$$

The NNI was used to indicate the N status for each experimental plot, independent of the growth stage and differing biomass levels. The NNI was calculated by Equation (4) [69]:

$$
\mathrm{NNI}=N_{a c t} / N_{c}
$$

where $N_{a c t}$ is the actual $\mathrm{N}$ concentration, and $N_{c}$ is the critical $\mathrm{N}$ concentration as a percentage of the aboveground dry matter expressed in \% DM. The $N_{c}$ for winter wheat was described by Equation (5) [70]:

$$
N_{c}=4.15 \times W^{-0.38}
$$

where $W$ is the aboveground biomass, expressed in $\mathrm{Mg}$ dry matter (DM) ha ${ }^{-1}$. 


\subsection{Data Analysis Methods}

Five traditional PR methods (linear, logarithmic, power, exponential, and second-order polynomial) and the MLR and GPR methods were used to establish relationships between wheat $\mathrm{N}$ parameters and spectral VIs in this study. For the PR methods, $70 \%$ of the samples were used to build the models, and 30\% were used to validate them. A stepwise MLR was used to estimate the winter wheat $\mathrm{N}$ status by recursively applying multiple regression.

Compared to other machine learning regression approaches, the parameter optimization of GPR is simpler and can be automatically completed by maximizing the marginal likelihood in the training set [34]. The core of the kernel method for GPR is the squared exponential. The use of a flexible kernel function (covariance function) generally suffices for tackling most regression problems and is beneficial if prior knowledge is weak [37]. This is an opportunity to exploit asymmetries in the feature space by including a parameter per feature, as in the very common anisotropic squared exponential (SE) kernel function:

$$
K\left(x_{i}, x_{j}\right)=\gamma \exp \left(-\sum_{b=1}^{B} \frac{\left(x_{i}^{b}-x_{j}^{b}\right)^{2}}{2 \sigma_{b}^{2}}\right)
$$

where $\gamma$ is a scaling factor; $\sigma_{b}$ is the length scale per input feature, $b=1, \ldots, B$; and $x_{i}^{b}$ represents the $b$ th feature of the input feature vector $x_{i}$. A smaller value of $\sigma_{b}$ indicates a higher level of informative content of this certain image feature. Verrelst et al. [34] integrated this property and SBBR as a new feature selection algorithm, in which the least significant feature with the highest $\sigma_{b}$ was removed at each iteration and a new GPR model was retrained with the remaining features only. A feature combination would eventually be identified by the feature selection algorithm. To enable the automated identification of the best-performing features for any regression problem, this feature selection algorithm was automated and integrated into a user-friendly tool named GPR-BAT [34].

In this study, GPR with SBBR was used firstly to identify the best VI combinations for different $\mathrm{N}$ parameters, and then MLR and GPR were used to build N parameter estimation models based on those VI combinations. The 10-fold cross-validation technique was used to determine the optimal number of latent factors based on the lowest root mean square error (RMSE). The accuracy of each model was evaluated by the coefficient of determination $\mathrm{R}^{2}$, RMSE, the mean absolute error (MAE), and the Nash-Sutcliffe modeling efficiency (NSE). The equations used to calculate RMSE, MAE, and NSE are presented in Table 5.

Table 5. Statistics computed to compare the results of the different VIs used for the N parameter estimation.

\begin{tabular}{cccc}
\hline Statistics & Formula & Character & Reference \\
\hline Root mean square error (RMSE) & RMSE $=\sqrt{\frac{\sum_{i}^{n}\left(\hat{y}_{i}-y_{i}\right)^{2}}{n}}$ & from 0 to $+\infty$, optimum 0 & [71] \\
Mean absolute error (MAE) & MAE $=\sum_{i=1}^{n}\left|\hat{y}_{i}-y_{i}\right| / n$ & from 0 to $+\infty$, optimum 0 & [72] \\
Nash-Sutcliffe efficiency (NSE) & NSE $=1-\sum_{i=1}^{n}\left(y_{i-} \hat{y}_{i}\right)^{2} / \sum_{i=1}^{n}\left(y_{i}-\bar{y}\right)^{2}$ & from $-\infty$ to 1, optimum 1 & {$[73]$} \\
\hline
\end{tabular}

Notes: $\hat{y}_{i}$ is the predicted value of the ith observation, $y_{i}$ is the measured value of the ith observation, $\bar{y}$ is the average of the measured values, and $\mathrm{n}$ is the number of observations in the calibration set.

\section{Results}

\subsection{Variation in Winter Wheat N Indicators}

Table 6 describes the variation in the winter wheat $\mathrm{N}$ indicators for different growth stages. PNC had the most variation $(\mathrm{CV}=49.46 \%$ across growth stages), followed by LNC $(\mathrm{CV}=32.34 \%)$ and NNI $(\mathrm{CV}=18.59 \%)$. At Feekes stage 5, the greatest difference occurred in NNI, which ranged from 0.74 to 1.58. PNC had more variation at Feekes stage 5 $(\mathrm{CV}=13.42 \%)$ than at Feekes stages $11(\mathrm{CV}=8.99 \%)$. The CV for LNC increased from $11.30 \%$ to $13.42 \%$ from Feekes 5 to Feekes 11 . The CV for NNI decreased from $17.17 \%$ at Feekes 5 to $11.97 \%$ at Feekes 11 . 
Table 6. Descriptive statistics of winter wheat LNC, PNC, and NNI across different growth stages.

\begin{tabular}{cccccccc}
\hline Growth Stage & Parameter & Min & Max & Mean & Range & Std & CV (\%) \\
\hline \multirow{2}{*}{ Feekes 5 } & LNC (\%) & 3.07 & 5.16 & 4.33 & 2.09 & 0.49 & 11.30 \\
& PNC (\%) & 2.60 & 4.67 & 3.77 & 2.07 & 0.51 & 13.42 \\
& NNI & 0.74 & 1.58 & 1.14 & 0.84 & 0.19 & 17.17 \\
\hline \multirow{2}{*}{ Feekes 11 } & LNC (\%) & 1.08 & 2.99 & 2.32 & 1.92 & 0.31 & 13.42 \\
& PNC (\%) & 0.77 & 1.58 & 1.33 & 0.81 & 0.12 & 8.99 \\
& NNI & 0.44 & 1.17 & 0.89 & 0.73 & 0.11 & 11.97 \\
\hline \multirow{2}{*}{ Feekes 5-11 } & LNC (\%) & 1.08 & 5.16 & 3.33 & 4.08 & 1.08 & 32.34 \\
& PNC (\%) & 0.77 & 4.67 & 2.55 & 3.90 & 1.26 \\
& NNI & 0.44 & 1.58 & 1.00 & 1.14 & 0.20 & 18.46 \\
\hline
\end{tabular}

\subsection{Relationships between Wheat $N$ and VIs for Different Sensors}

After the correlation analysis between the VIs and the three N parameters, the VI with the highest correlation coefficient was selected to establish the $\mathrm{N}$ estimation model. Table 7 lists the VIs and their $\mathrm{R}^{2}$ and RMSE for the best models for wheat LNC, PNC, and NNI through traditional PR methods. For the PR methods, $70 \%$ of the samples ( 70 samples) were used to build the models, and 30\% (34 samples) were used to validate them. It could be observed, at wheat Feekes stage 5, that the Dualex- and Multiplex-based VIs had a stronger correlation with wheat LNC, PNC, and NNI. The $\mathrm{R}^{2}$ for the LNC and PNC models based on the Dualex NBI reached 0.80 and 0.79 , respectively. At the late wheat growth stage, canopy-level VIs performed better than the leaf-level VIs. The RGB and ASD VIs performed better than the Dualex and Multiplex VIs for LNC, PNC, and NNI estimation. RGB camerabased $\mathrm{r}$ performed best for LNC estimation at wheat Feekes stage 11, followed by ASD $\mathrm{mND}_{705}$, and Dualex CHI. For PNC estimation, ASD NDRE performed best, followed by the RGB camera-based ExR. Multiplex performed best on the wheat $\mathrm{N}$ status estimation across wheat stages (Feekes 5-11), and the $\mathrm{R}^{2}$ reached 0.87 for BRR_FRF and LNC, 0.86 for BRR_FRF and PNC, and 0.56 for NBI_G and NNI.

Table 7. Relationship between wheat $\mathrm{N}$ variables and VIs from different sensors at different growth stages $(\mathrm{n}=104)$.

\begin{tabular}{|c|c|c|c|c|c|c|c|c|c|c|c|c|c|}
\hline \multirow{2}{*}{ Sensor } & \multirow{2}{*}{ Feekes Stage } & \multicolumn{4}{|c|}{ LNC (\%) } & \multicolumn{4}{|c|}{ PNC (\%) } & \multicolumn{4}{|c|}{ NNI } \\
\hline & & Model & VI & $\mathbf{R}^{2}$ & RMSE & Model & VI & $\mathbf{R}^{2}$ & RMSE & Model & VI & $R^{2}$ & RMSE \\
\hline \multirow{3}{*}{ RGB } & 5 & Poly & NPCI & $0.43 * *$ & 0.23 & Poly & ExR & $0.33 * *$ & 0.10 & Poly & ExR & $0.31^{* *}$ & 0.09 \\
\hline & 11 & Poly & NDI & $0.39 * *$ & 0.38 & Poly & NDI & $0.39 * *$ & 0.26 & Exp & NDI & $0.36 * *$ & 0.16 \\
\hline & $5-11$ & Poly & $\mathrm{r}$ & $0.61^{* *}$ & 0.68 & Pow & ExR & 0.62 ** & 0.40 & Log & ExR & $0.37^{* *}$ & 0.16 \\
\hline \multirow{3}{*}{ ASD } & 5 & Poly & NDIopt & 0.19 & 0.44 & Poly & NDIopt & 0.19 & 0.30 & Poly & $\mathrm{SR}_{(553,537)}$ & $0.30 * *$ & 0.16 \\
\hline & 11 & Poly & $\mathrm{mND}_{705}$ & $0.40^{* *}$ & 0.24 & Poly & NDRE & $0.46^{* *}$ & 0.09 & Poly & NDRE & $0.39 * *$ & 0.08 \\
\hline & $5-11$ & Poly & NDIopt & $0.85^{* *}$ & 0.43 & Poly & NDIopt & $0.84^{* *}$ & 0.26 & Log & NDIopt & 0.53 ** & 0.14 \\
\hline \multirow{3}{*}{ Multiplex } & 5 & Poly & FLAV & $0.55^{* *}$ & 0.33 & Poly & FLAV & $0.52 * *$ & 0.24 & Poly & NBI_R & $0.42 * *$ & 0.15 \\
\hline & 11 & Poly & SFR_R & $0.34^{* *}$ & 0.25 & Poly & SFR_R & 0.23 & 0.11 & Poly & SFR_R & $0.21^{*}$ & 0.10 \\
\hline & $5-11$ & Poly & BRR_FRF & $0.87^{* *}$ & 0.39 & Poly & BRR_FRF & $0.86^{* *}$ & 0.24 & Poly & NBI_G & $0.56^{* *}$ & 0.13 \\
\hline \multirow{3}{*}{ Dualex } & 5 & Log & NBI & $0.80^{* *}$ & 0.22 & Pow & NBI & $0.79 * *$ & 0.23 & Lin & NBI & $0.49^{* *}$ & 0.14 \\
\hline & 11 & Poly & $\mathrm{CHI}$ & $0.36^{* *}$ & 0.27 & Log & $\mathrm{CHI}$ & 0.16 & 0.11 & Log & $\mathrm{CHI}$ & 0.20 * & 0.10 \\
\hline & $5-11$ & Poly & NBI & 0.57 ** & 0.72 & Poly & NBI & 0.50 ** & 0.92 & Exp & NBI & $0.46^{* *}$ & 0.15 \\
\hline
\end{tabular}

Note: Lin: linear, Exp: exponential, Pow: power, Poly: second-order polynomial, Log: logarithmic; ${ }^{* *} \mathrm{r}(0.01,70)$ $=0.302$, indicates significance at the 0.01 probability level; ${ }^{*} \mathrm{r}(0.05,70)=0.232$, indicates significance at the 0.05 probability level.

\subsection{Wheat N Estimation through UAV-Level VIs}

GPR and MLR were used to estimate the relationships between the RGB camera VIs and $\mathrm{N}$ variables. The 10 -fold cross-validation technique was used to determine the optimal number of latent factors based on the lowest root mean square error (RMSE). Table 8 lists the cross-validation results for models built by the selected VI combinations and all VIs through the GPR and MLR methods. The VI combinations for different $\mathrm{N}$ variables were selected by the GPR-SBBR feature selection algorithm. 
Table 8. Cross-validation results for N estimation through GPR and MLR based on UAV-mounted RGB camera VIs.

\begin{tabular}{|c|c|c|c|c|c|c|c|c|c|c|c|}
\hline \multirow{2}{*}{$\begin{array}{c}\mathrm{N} \\
\text { Variable }\end{array}$} & \multirow{2}{*}{$\begin{array}{c}\text { Feekes } \\
\text { Stage }\end{array}$} & \multirow{2}{*}{ VI } & \multicolumn{2}{|c|}{ GPR-SBBR } & \multicolumn{2}{|c|}{ MLR } & \multirow{2}{*}{ VIs } & \multicolumn{2}{|c|}{ GPR } & \multicolumn{2}{|c|}{ MLR } \\
\hline & & & $\mathbf{R}^{2}$ & RMSE & $\mathbf{R}^{2}$ & RMSE & & $\mathbf{R}^{2}$ & RMSE & $\mathbf{R}^{2}$ & RMSE \\
\hline \multirow{3}{*}{ LNC } & 5 & $\mathrm{~B}, \mathrm{~b}$ & 0.44 & 0.37 & 0.43 & 0.37 & All 14 VIs & 0.41 & 0.37 & 0.28 & 0.43 \\
\hline & 11 & NPCI & 0.43 & 0.24 & 0.36 & 0.25 & All 14 VIs & 0.40 & 0.25 & 0.33 & 0.26 \\
\hline & $5-11$ & $\mathrm{~B}, \mathrm{~g}, \mathrm{CVI} 2$ & 0.82 & 0.46 & 0.62 & 0.67 & All 14 VIs & 0.81 & 0.47 & 0.68 & 0.62 \\
\hline \multirow{3}{*}{ PNC } & 5 & $\mathrm{~B}, \mathrm{~b}$ & 0.42 & 0.38 & 0.41 & 0.38 & All 14 VIs & 0.39 & 0.39 & 0.29 & 0.44 \\
\hline & 11 & G, NDI & 0.41 & 0.09 & 0.29 & 0.10 & All 14 VIs & 0.38 & 0.09 & 0.40 & 0.09 \\
\hline & $5-11$ & $\mathrm{~B}, \mathrm{~g}, \mathrm{CVI} 2$ & 0.89 & 0.43 & 0.59 & 0.82 & All 14 VIs & 0.87 & 0.45 & 0.67 & 0.74 \\
\hline \multirow{3}{*}{ NNI } & 5 & $\mathrm{~B}, \mathrm{~b}$ & 0.35 & 0.16 & 0.35 & 0.16 & All 14 VIs & 0.28 & 0.16 & 0.33 & 0.16 \\
\hline & 11 & R, NDI, CVI2 & 0.33 & 0.09 & 0.34 & 0.09 & All 14 VIs & 0.33 & 0.09 & 0.26 & 0.10 \\
\hline & $5-11$ & $\mathrm{~B}, \mathrm{G}, \mathrm{g}, \mathrm{NDI}, \mathrm{CVI} 2, \mathrm{CVI} 3$ & 0.54 & 0.14 & 0.38 & 0.16 & All 14 VIs & 0.54 & 0.13 & 0.45 & 0.15 \\
\hline
\end{tabular}

It can be observed in Table 8 that the best VI combinations for LNC, PNC, and NNI estimation at the different wheat growth stages are different. At Feekes stags 5, the VI combinations selected by the GPR-SBBR algorithm for LNC, PNC, and NNI estimation were all $\mathrm{B}$ and $\mathrm{b}$, indicating that the RGB camera VIs $\mathrm{B}$ and $\mathrm{b}$ can be used to identify the $\mathrm{N}$ status at the wheat growth stage.

GPR models built by the selected VIs had a higher cross-validation $\mathrm{R}^{2}$ compared to the GPR models built by all VIs. MLR models based on the selected VIs achieved a higher $R^{2}$ at Feekes stage 5 and Feekes stage 11 for LNC and NNI estimation. However, MLR models built by all VIs performed better than MLR models built by the selected VIs on N status estimation across different wheat growth stages (Feekes stage 5-11).

\subsection{Wheat N Estimation through Canopy-Level VIs}

Tables 9 and 10 list the cross-validation results for the $\mathrm{N}$ estimation models through GPR and MLR based on canopy-level VIs. Table 9 indicates that for LNC estimation, the best ASD VI combinations were TBI1, NDIopt, and TBI2 at wheat Feekes stage 5, SR $(700,670)$, $\mathrm{SR}_{(418,405)}$, and $\mathrm{SR}_{(740,720)}$ at Feekes stage 11 , and $\mathrm{SR}_{(418,405)}$, TBI1, and PPR across Feekes 5-11. For PNC estimation, the optimal VI combinations were TBI1, NDIopt, and TBI2 at wheat Feekes stage 5, $\mathrm{SR}_{(700,670)}, \mathrm{SR}_{(418,405)}$, and $\mathrm{SR}_{(740,720)}$ at Feekes stage 11, and TBI1, PPR, REV, and REFD across Feekes 5-11. The best VIs for NNI estimation included two VIs (MSAVI and PPR) at wheat Feekes stage 5, four VIs (NDWI, MCARI, MSAVI, and PVR) at wheat Feekes stage 11 , and five VIs $\left(\mathrm{SR}_{(418,405)}\right.$, NDIopt, MSAVI, MCARI1, and PPR) at wheat Feekes stage 5-11. It can be seen in Table 9 that the LNC, PNC, and NNI estimation models built by GPR with the selected VIs performed better than those built by the other three methods. MLR with all ASD VIs had a higher cross-validation $R^{2}$ than MLR with the selected ASD VIs or GPR with all ASD VIs at wheat Feekes stage 5 and Feekes stage 11.

Table 10 lists the LNC, PNC, and NNI estimation results through both the GPR method and the MLR method. The best-performing Multiplex VI combinations for LNC estimation were SFR_G, FLAV, and NBI_R at wheat Feekes stage 5, NBI_R and SFR_R at wheat Feekes stage 11, and SFR_R, BRR_FRF, and NBI_R at wheat Feekes stage 5-11. The best Multiplex VI combinations for PNC were SFR_R, FLAV, and NBI_R at wheat Feekes stage 5, SFR_R at wheat Feekes stage 11, and SFR_R, BRR_FRF, and NBI_G at wheat Feekes stage 5-11. For NNI, Multiplex FLAV and FER_RG at wheat Feekes growth stage 5, SFR_G and SFR_R at wheat Feekes growth stage 11, and SFR_G, SFR_R, and NBI_G at wheat Feekes stage 5-11 performed well. The cross-validation $\mathrm{R}^{2}$ values for LNC, PNC, and NNI estimated by GPR with the selected VIs were higher than those estimated by GPR or MLR with all VIs at wheat Feekes stage 5 and Feekes stage 11. 
Table 9. Cross-validation results for N estimation through GPR and MLR methods based on ASD VIs.

\begin{tabular}{|c|c|c|c|c|c|c|c|c|c|c|c|}
\hline \multirow{2}{*}{$\frac{\mathrm{N}}{\text { Variable }}$} & \multirow{2}{*}{$\begin{array}{c}\text { Feekes } \\
\text { Stage }\end{array}$} & \multirow{2}{*}{ VI } & \multicolumn{2}{|c|}{ GPR-SBBR } & \multicolumn{2}{|c|}{ MLR } & \multirow{2}{*}{ VIs } & \multicolumn{2}{|c|}{ GPR } & \multicolumn{2}{|c|}{ MLR } \\
\hline & & & $\mathbf{R}^{2}$ & RMSE & $\mathbf{R}^{2}$ & RMSE & & $\mathbf{R}^{2}$ & RMSE & $\mathbf{R}^{2}$ & RMSE \\
\hline \multirow{3}{*}{ LNC } & 5 & TBI1, NDIopt, TBI2 & 0.47 & 0.36 & 0.31 & 0.41 & All 28 VIs & 0.28 & 0.42 & 0.34 & 0.42 \\
\hline & 11 & $\begin{array}{l}\mathrm{SR}_{(700,670)}, \mathrm{SR}_{(418,405)} \\
\mathrm{SR}_{(740,720)}\end{array}$ & 0.51 & 0.22 & 0.33 & 0.25 & All 28 VIs & 0.39 & 0.26 & 0.42 & 0.26 \\
\hline & 5-11 & $\begin{array}{l}\mathrm{SR}_{(418,405),} \text { TBI1, PPR, } \\
\text { PRI, REFD }\end{array}$ & 0.93 & 0.29 & 0.88 & 0.37 & All 28 VIs & 0.92 & 0.30 & 0.91 & 0.34 \\
\hline \multirow{3}{*}{ PNC } & 5 & TBI1, NDIopt, TBI2 & 0.46 & 0.37 & 0.32 & 0.42 & All 28 VIs & 0.27 & 0.44 & 0.33 & 0.44 \\
\hline & 11 & $\begin{array}{l}\mathrm{SR}_{(418,405)}, \mathrm{NDI} \text { (opt, } \\
\text { RDVI, REFD }\end{array}$ & 0.49 & 0.09 & 0.38 & 0.09 & All 28 VIs & 0.35 & 0.10 & 0.38 & 0.10 \\
\hline & 5-11 & TBI1, PPR, REV, REFD & 0.96 & 0.27 & 0.89 & 0.42 & All 28 VIs & 0.95 & 0.28 & 0.94 & 0.31 \\
\hline \multirow{3}{*}{ NNI } & 5 & MSAVI, PPR & 0.51 & 0.14 & 0.51 & 0.14 & All 28 VIs & 0.41 & 0.15 & 0.35 & 0.17 \\
\hline & 11 & $\begin{array}{l}\text { NDWI, MCARI, } \\
\text { MSAVI, PVR }\end{array}$ & 0.39 & 0.08 & 0.21 & 0.10 & All 28 VIs & 0.28 & 0.10 & 0.21 & 0.10 \\
\hline & 5-11 & $\begin{array}{c}\text { SR }_{(418,405)}, \text { NDIopt, MSAVI, } \\
\text { MCARI1, PPR }\end{array}$ & 0.66 & 0.12 & 0.56 & 0.13 & All 28 VIs & 0.59 & 0.12 & 0.59 & 0.13 \\
\hline
\end{tabular}

Table 10. Cross-validation results for N estimation through GPR and MLR methods based on Multiplex VIs.

\begin{tabular}{|c|c|c|c|c|c|c|c|c|c|c|c|}
\hline \multirow{2}{*}{$\frac{\mathrm{N}}{\text { Variable }}$} & \multirow{2}{*}{$\begin{array}{c}\text { Feekes } \\
\text { Stage }\end{array}$} & \multirow{2}{*}{ VI } & \multicolumn{2}{|c|}{ GPR-SBBR } & \multicolumn{2}{|c|}{ MLR } & \multirow{2}{*}{ VIs } & \multicolumn{2}{|c|}{ GPR } & \multicolumn{2}{|c|}{ MLR } \\
\hline & & & $\mathbf{R}^{2}$ & RMSE & $\mathbf{R}^{2}$ & RMSE & & $\mathbf{R}^{2}$ & RMSE & $\mathbf{R}^{2}$ & RMSE \\
\hline \multirow{3}{*}{ LNC } & 5 & SFR_G, FLAV, NBI_R & 0.59 & 0.31 & 0.59 & 0.31 & All 9 VIs & 0.57 & 0.31 & 0.58 & 0.32 \\
\hline & 11 & SFR_R & 0.44 & 0.28 & 0.27 & 0.27 & All 9 VIs & 0.39 & 0.30 & 0.16 & 0.29 \\
\hline & $5-11$ & SFR_R, BRR_FRF, NBI_R & 0.93 & 0.29 & 0.88 & 0.38 & All 9 VIs & 0.93 & 0.30 & 0.90 & 0.34 \\
\hline \multirow{3}{*}{ PNC } & 5 & SFR_R, FLAV, NBI_R & 0.58 & 0.34 & 0.57 & 0.34 & All 9 VIs & 0.53 & 0.34 & 0.53 & 0.35 \\
\hline & 11 & SFR_R & 0.34 & 0.10 & 0.15 & 0.11 & All 9 VIs & 0.25 & 0.11 & 0.24 & 0.11 \\
\hline & $5-11$ & SFR_R, BRR_FRF, NBI_G & 0.96 & 0.25 & 0.90 & 0.41 & All 9 VIs & 0.96 & 0.26 & 0.93 & 0.35 \\
\hline \multirow{3}{*}{ NNI } & 5 & FLAV, FER_RG & 0.52 & 0.34 & 0.52 & 0.14 & All 9 VIs & 0.52 & 0.14 & 0.44 & 0.15 \\
\hline & 11 & SFR_G,SFR_R & 0.31 & 0.09 & 0.24 & 0.09 & All 9 VIs & 0.18 & 0.10 & 0.25 & 0.10 \\
\hline & $5-11$ & SFR_G, SFR_R, NBI_G & 0.59 & 0.13 & 0.58 & 0.13 & All 9 VIs & 0.58 & 0.13 & 0.58 & 0.13 \\
\hline
\end{tabular}

\subsection{Wheat N Estimation through Leaf-Level VIs}

Table 11 lists the cross-validation results for the three $\mathrm{N}$ parameters estimated through the GPR and MLR methods based on Dualex VIs. It can be seen in Table 11 that the best-performing VI for LNC, PNC, and NNI was NBI at wheat Feekes stage 5. At wheat Feekes stage 11, Chl performed best for LNC, PNC, and NNI estimation. These results indicate that the Dualex sensor can detect the leaf $\mathrm{N}$ status at different wheat growth stages, especially at Feekes stage 5. During Feekes stage 5-11, the combination of the Dualex NBI and Chl performed best for estimating LNC, PNC, and NNI.

Table 11. Cross-validation results through GPR and MLR methods at different wheat growth stages.

\begin{tabular}{|c|c|c|c|c|c|c|c|c|c|c|c|}
\hline \multirow{2}{*}{$\frac{\mathrm{N}}{\text { Variable }}$} & \multirow{2}{*}{$\begin{array}{c}\text { Feekes } \\
\text { Stage }\end{array}$} & \multirow{2}{*}{ VI } & \multicolumn{2}{|c|}{ GPR-SBBR } & \multicolumn{2}{|c|}{ MLR } & \multirow{2}{*}{ VIs } & \multicolumn{2}{|c|}{ GPR } & \multicolumn{2}{|c|}{ MLR } \\
\hline & & & $\mathbf{R}^{2}$ & RMSE & $R^{2}$ & RMSE & & $\mathbf{R}^{2}$ & RMSE & $\mathbf{R}^{2}$ & RMSE \\
\hline \multirow{3}{*}{ LNC } & 5 & NBI & 0.80 & 0.22 & 0.79 & 0.23 & All 3 VIs & 0.77 & 0.22 & 0.80 & 0.22 \\
\hline & 11 & Chl & 0.55 & 0.21 & 0.12 & 0.31 & All 3 VIs & 0.52 & 0.21 & 0.10 & 0.36 \\
\hline & $5-11$ & NBI, Chl & 0.83 & 0.43 & 0.60 & 0.69 & All 3 VIs & 0.83 & 0.43 & 0.74 & 0.56 \\
\hline \multirow{3}{*}{ PNC } & 5 & NBI & 0.79 & 0.23 & 0.79 & 0.23 & All 3 VIs & 0.78 & 0.22 & 0.79 & 0.23 \\
\hline & 11 & Chl & 0.20 & 0.11 & 0.11 & 0.11 & All 3 VIs & 0.12 & 0.12 & 0.16 & 0.11 \\
\hline & $5-11$ & NBI, Chl & 0.82 & 0.55 & 0.55 & 0.86 & All 3 VIs & 0.81 & 0.54 & 0.67 & 0.74 \\
\hline \multirow{3}{*}{ NNI } & 5 & NBI & 0.51 & 0.14 & 0.49 & 0.14 & All 3 VIs & 0.51 & 0.14 & 0.47 & 0.14 \\
\hline & 11 & Chl & 0.27 & 0.10 & 0.10 & 0.10 & All 3 VIs & 0.22 & 0.10 & 0.26 & 0.09 \\
\hline & 5-11 & NBI, Chl & 0.60 & 0.13 & 0.42 & 0.15 & All 3 VIs & 0.59 & 0.13 & 0.48 & 0.15 \\
\hline
\end{tabular}




\section{Discussion}

Ground-based spectrometers are considered capable of monitoring crop trait expressions and nutrients [74,75]; however, data collection with handheld sensors has the limitations of instability, low sensing efficiency, and high cost [76]. In this study, variable-rate $\mathrm{N}$ fertilization treatments in winter wheat were carried out to represent the reality, which resulted in different winter wheat $\mathrm{N}$ nutrition conditions (Tables 1 and 6). Four different sensors were used to obtain crop growth information during two winter wheat critical growth stages. This allowed a preliminary assessment of the utility of the handheld leaf and canopy sensors as well as the UAV-mounted sensor in the estimation of $\mathrm{N}$ status indictors of winter wheat. The predictive performances of the four sensors were compared using different modeling methods (PR, MLR, and GPR).

\subsection{N Estimation Comparison for Different Sensors}

We investigated the wheat $\mathrm{N}$ estimation capability for different sensors by comparing the cross-validation $\mathrm{R}^{2}$ of the models. Figure 2 clearly shows that different sensors have different capabilities in $\mathrm{N}$ status detection during the wheat growth stage.

It can be observed in Figure 2a,b that the Dualex sensor had an obvious advantage in LNC and PNC estimation at wheat Feekes stage 5, and the $\mathrm{R}^{2}$ for different modeling methods varied from 0.77 to 0.80 for LNC, and from 0.78 to 0.79 for PNC. The Multiplex sensor can also detect LNC and PNC better than the ASD spectrometer or the RGB camera at the early wheat growth stage because it can eliminate erroneous signals from bare soil or distinguish between different $\mathrm{N}$ treatments in shadow with full sunlight. At Feekes stage 11, due to the biomass saturation, the correlations between $\mathrm{N}$ status and the VIs of the Dualex and Multiplex sensors decreased quickly. The modeling mean $\mathrm{R}^{2}$ decreased from 0.79 to 0.33 for Dualex, and from 0.58 to 0.32 for Multiplex, over the winter wheat growth stages. Compared with the other sensors, the ASD spectrometer performed well in LNC and PNC estimation through GPR with the selected VIs at winter wheat Feekes stage 11. The estimation $\mathrm{R}^{2}$ reached 0.51 for LNC and 0.49 for PNC. For NNI detection, the Dualex sensor worked relatively well at wheat Feekes stage 5 , with a mean $R^{2}$ of 0.50 for different regression methods, followed by the Multiplex sensor, with a mean $R^{2}$ of 0.48 for different regression methods. All sensors did not perform well in NNI estimation at wheat Feekes stage 11 in this study. When data from the two stages were combined (Feekes 5-11), the modeling accuracy for the three $\mathrm{N}$ parameters all increased obviously. It can be observed in Figure 2 that the ASD and Multiplex sensors can detect LNC and PNC better than the RGB camera and the Dualex sensor. The $R^{2}$ values are all greater than 0.90 for the ASD and Multiplex sensors.

Numerous studies have revealed that, at the leaf level, there is a well-established correlation between photosynthetic capacity and $\mathrm{N}$ content [27], while at the scale of canopies, reflectance patterns represent the integrated effects of leaf water content, biochemical constituents, and various components of the plant structure [77]. As reviewed by Tremblay et al., determining $\mathrm{N}$ status in plants by means of chlorophyll fluorescence can overcome some of the limitations of reflectance-based chlorophyll methods [10]. The Dualex VIs, namely, the Nitrogen Balance Index (NBI) and the chlorophyll index (CHI), seem to be good indicators to evaluate the $\mathrm{N}$ conditions in wheat at the early growth stage. This was also confirmed by the results of this study. The Multiplex sensor can overcome the deficiency of a chlorophyll meter because it is able to distinguish $\mathrm{N}$ treatments equally well in shadow or full sunlight, and at any time during the day [10]. Multiplex performs better in estimating wheat LNC, PNC, and NNI than ASD at the early wheat growth stage, while ASD can detect the wheat $\mathrm{N}$ indicators more accurately than Multiplex at the late wheat growth stage. 


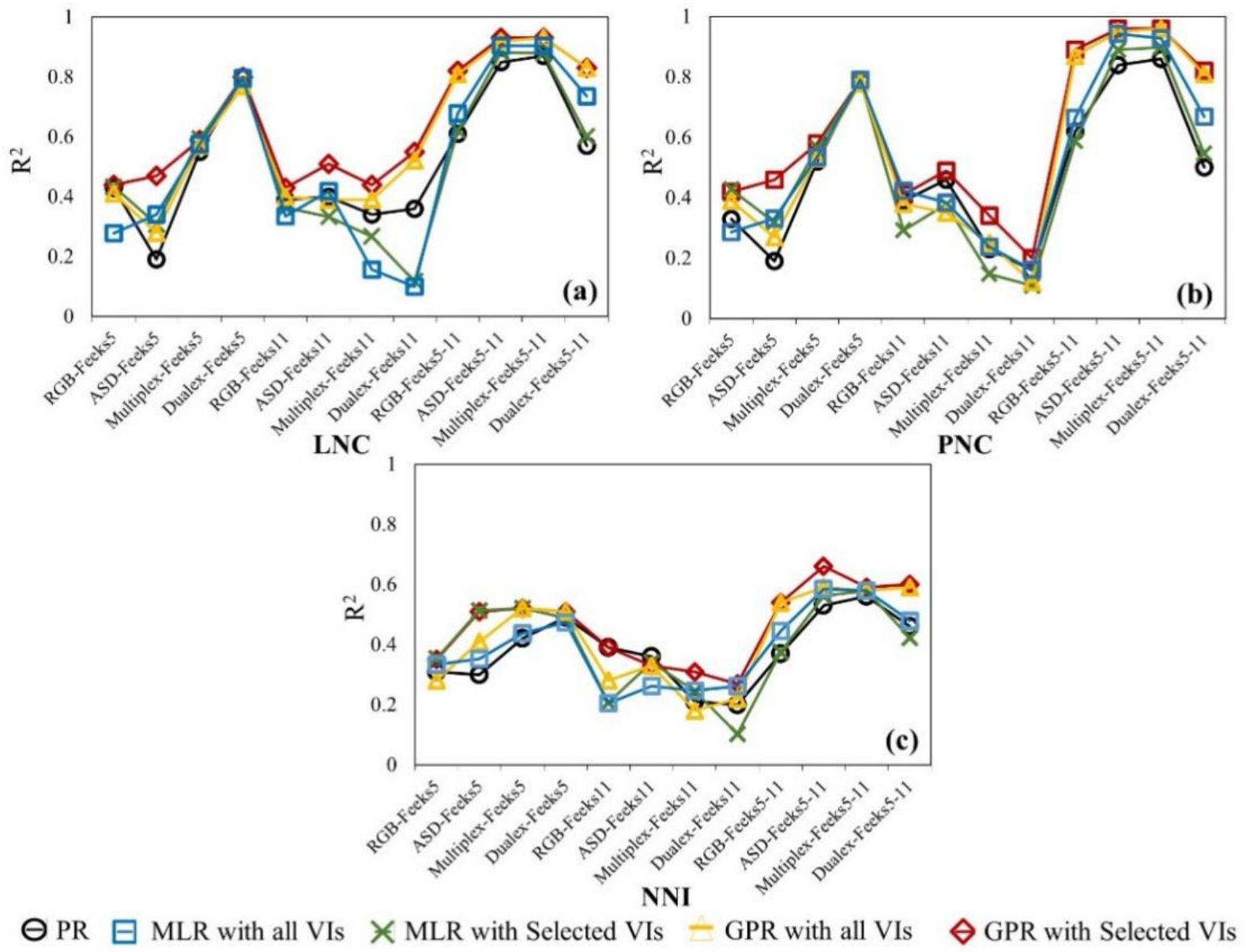

Figure 2. Cross-validation $\mathrm{R}^{2}$ for LNC (a), PNC (b), and NNI (c) estimation with different sensors through PR, MLR, and GPR methods.

\subsection{Accuracy Evaluation of GPR, MLR, and PR Methods}

In this study, the GPR model combined with the SBBR algorithm was used to obtain the optimum N-sensitive VI combinations for different sensors. Then, both the MLR and GPR models based on the VI combinations and all VIs (Tables 8-11), as well as the PR model (Table 7), were investigated for $\mathrm{N}$ estimation accuracy through comparing the models' $\mathrm{R}^{2}$ and RMSE. Figures 3 and 4 show the mean absolute error (MAE) and the Nash-Sutcliffe modeling efficiency (NSE) for LNC, PNC, and NNI through the PR, MLR, and GPR modeling methods.

The ideal MAE value is 0 from the range of 0 to positive infinity, while the optimum NSE value is 1 from the range of negative infinity to 1 . As shown in Figure 3, the MAE values for the LNC models built by GPR methods for different sensors are generally less than those of the PR and MLR methods. Meanwhile, the NSE values in Figure 4 indicate that the GPR methods have a higher accuracy, especially when modeling with the ASD and RGB VIs across different wheat growth stages. For PNC estimation, the PR method can obtain a lower MAE at wheat Feekes stage 5, while the GPR models perform better at wheat Feekes stage 11. For NNI estimation, GPR modeling with the selected Multiplex and ASD VIs has a higher MAE than the other methods, indicating that these two sensors may not be suitable for NNI estimation at the early wheat growth stage. It can be seen in Figures 3 and 4 that when the two stages are combined, GPR modeling with all VIs or the selected VIs can estimate N parameters with a lower MAE and a higher NSE than the other modeling methods.

Figure 5 shows the scatterplots of the estimated vs. measured LNC, PNC, and NNI through the GPR-SBBR process based on the best VIs for the four sensors. 


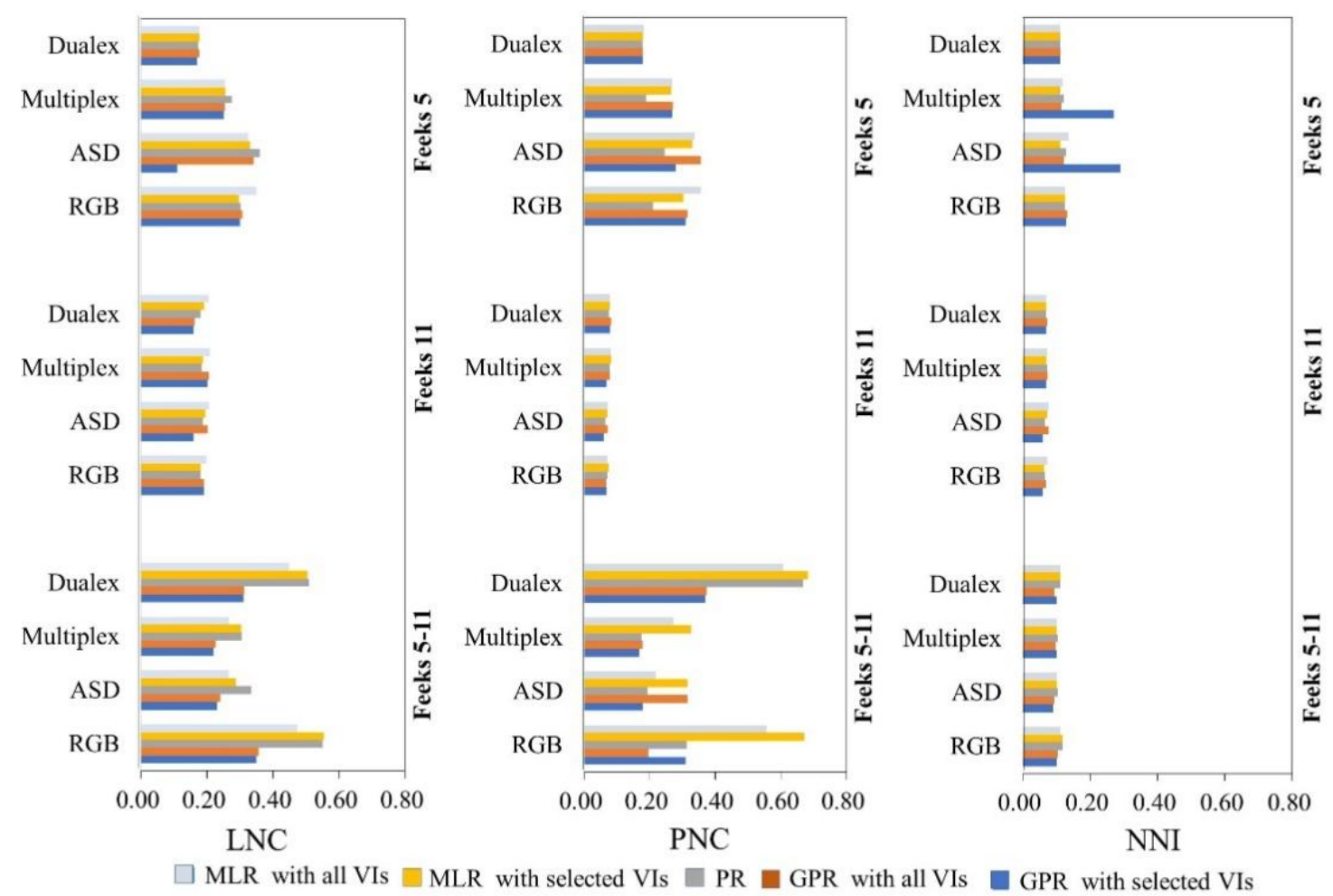

Figure 3. The MAE for LNC (left), PNC (middle), and NNI (right) estimation with different sensors through PR, MLR, and GPR methods.

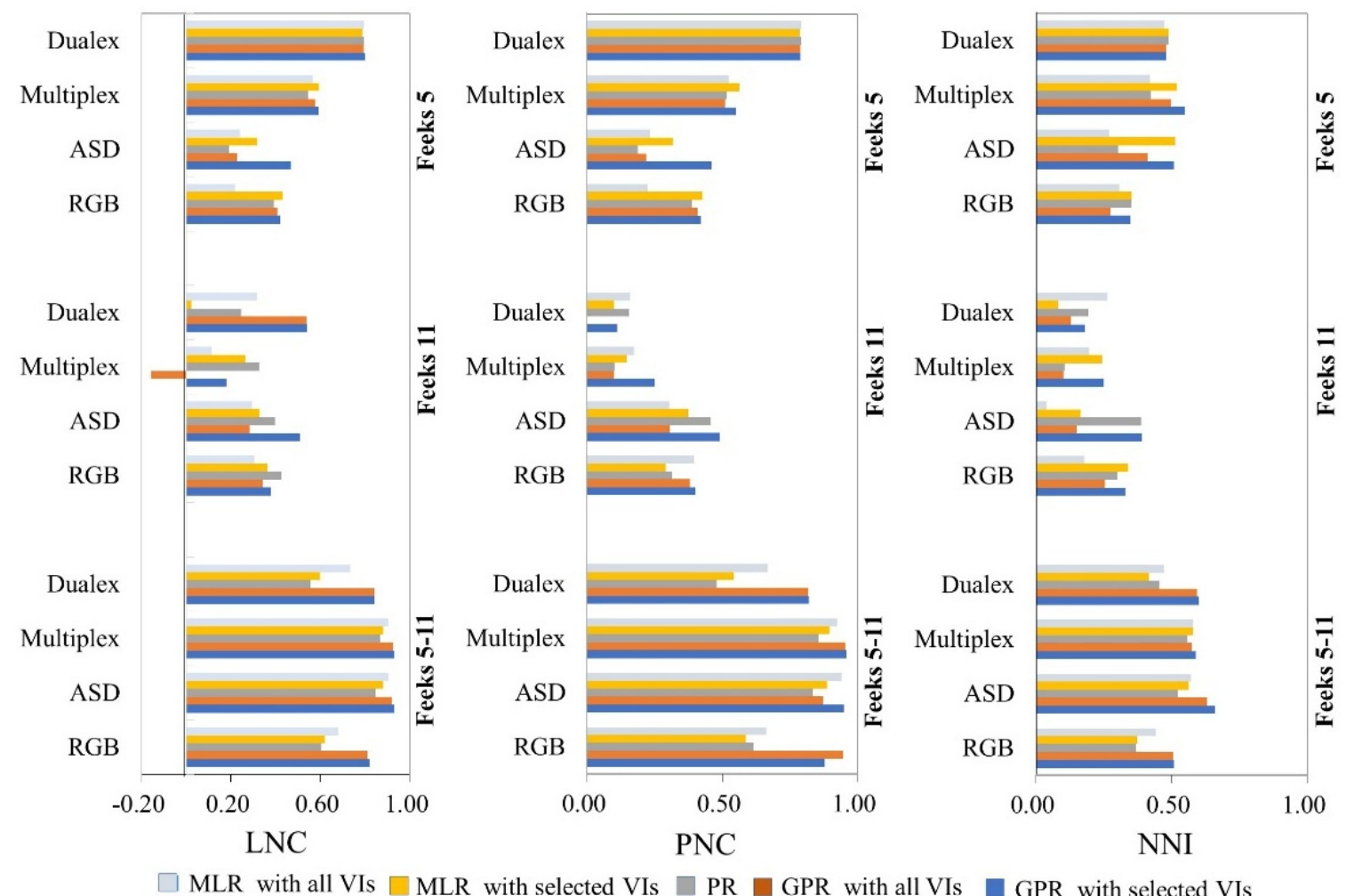

Figure 4. The NSE for LNC (left), PNC (middle), and NNI (right) estimation with different sensors through PR, MLR, and GPR methods. 

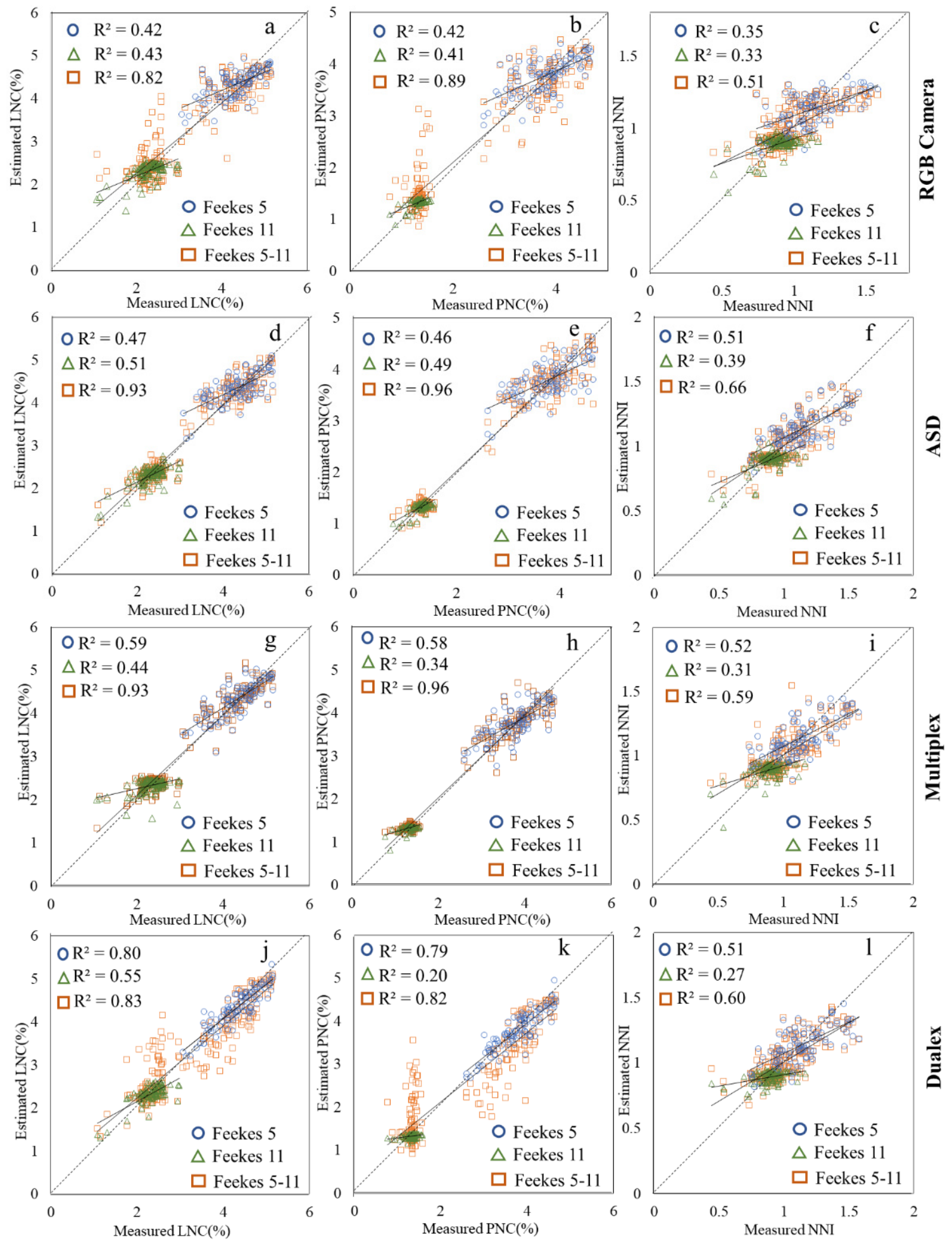

Figure 5. Measured vs. estimated LNC (left), PNC (middle), and NNI (right) values along the 1:1 line

through the GPR-SBBR method based on best VIs for four different sensors. (a) LNC based on RGB sensor; (b) PNC based on RGB sensor; (c) NNI based on RGB sensor; (d) LNC based on ASD sensor; (e) PNC based on ASD sensor; (f) NNI based on ASD sensor; (g) LNC based on Multiplex sensor; (h) PNC based on Multiplex sensor; (i) NNI based on Multiplex sensor; (j) LNC based on Dualex sensor; (k) PNC based on Dualex sensor; and (1) NNI based on Dualex sensor. 
Contrary to other methods, the training phase in GPR takes place in a Bayesian framework. Verrelst et al. compared GPR with parametric methods based on established and generic VIs [34]. GPR not only outperformed parametric linear regression methods but also offered additional interesting features that go far beyond what is typically available from parametric or non-parametric approaches [35]. In this study, the GPR model with the selected ASD VIs yielded an obviously higher accuracy for LNC and PNC estimation compared to the PR and MLR models. The result from this study is consistent with previous findings.

Apart from the GPR model, the $\mathrm{R}^{2}$, MAE, and NSE value variation for the MLR and PR models across different wheat growth stages indicates that these models could not produce reliable estimates of winter wheat $\mathrm{N}$ status indicators. RGB image-based VIs were used to estimate the $\mathrm{N}$ status of winter wheat in field conditions. The observed wheat $\mathrm{N}$ parameters were fairly well described by the image data with the GPR model, indicating that a digital camera can be used as a low-cost tool to estimate crop $\mathrm{N}$ status and deliver information for $\mathrm{N}$ management over a broader region.

The relationships between the VIs from different sensors and $\mathrm{N}$ status indicators at the early wheat growth stage were generally better than those at the late stage. The growth stage was found to have a significant effect on the relationships between VIs and N status indicators. This was also confirmed by the results of previous studies [3,38]. However, because the Multiplex or ASD sensor requires measurements made over the plant, covering a small area, it is difficult to apply this type of sensor in monitoring $\mathrm{N}$ status in larger areas. Although multispectral or hyperspectral images with near-infrared sensitivity can often convey more information than conventional RGB images, RGB cameras have been more frequently used due to their low cost and ease of use [78]. In this study, RGB imagebased VIs were used to estimate the nitrogen status of winter wheat canopies under field conditions. Compared with the other sensors, the UAV-mounted RGB camera is a better selection for crop growth and nutrition monitoring due to its ability to conduct the same type of assessment over hundreds or thousands of plots with a low cost and ease of use, as shown in this study. Different types of sensors can be carried by the UAV to detect the crop growth and nutrition status. The crop information extracted from UAV images is affected not only by the sensor type, but also by the UAV imaging conditions, such as the UAV flight height and speed. In this study, only one sensor (the RGB camera) was mounted on the UAV to test its ability to estimate crop N status. More research is needed to explore the feasibility of this type of camera and other sensors for estimating the spatial distribution of the $\mathrm{N}$ status of winter wheat and other crops under different UAV flight heights and speeds over large areas.

\section{Conclusions}

Crop nitrogen nutrition diagnosis is important for practicing precision farming. Proxi$\mathrm{mal}$ and airborne sensors provide useful information for the diagnosis of crop $\mathrm{N}$ nutritional status. In this study, a GPR method with the 10-fold cross-validation SBBR routine was used to identify the best VIs sensitive to wheat LNC, PNC, and NNI for four different sensors. The observed wheat $\mathrm{N}$ parameters were well described by the GPR and traditional PR methods throughout the two growth stages. The following conclusions can be drawn from this study:

At the early wheat growth stage, the Dualex NBI is a good leaf-level indicator for wheat LNC, PNC, and NNI estimation. Meanwhile, the combination of Multiplex SFR_G, FLAV, and NBI_R, the combination of SFR_R, FLAV, and NBI_R, and the combination of FLAV and FER_RG are the best canopy-level indicators for LNC, PNC, and NNI estimation at the early wheat growth stage. The results indicate that the optical fluorescence sensor provides more accurate estimates of winter wheat $\mathrm{N}$ status at a low-canopy coverage condition.

At the late wheat growth stage, the best ASD VIs, including the combination of $\mathrm{SR}_{(700,670)}, \mathrm{SR}_{(418,405)}$, and $\mathrm{SR}_{(740,720)}$, the combination of $\mathrm{SR}_{(418,405)}$, NDIopt, RDVI, and 
REFD, and the combination of NDWI, MCARI, MSAVI, and PVR, provided accurate estimates for wheat LNC, PNC, and NNI. The results indicate that the ASD sensor, which collects more detailed information, is an essential tool for $\mathrm{N}$ estimation at the late wheat growth stage, although the reflectance patterns of ASD represent the integrated effects of leaf water content, biochemical constituents, and various components of the plant structure.

This study reveals that the GPR with SBBR method provides more accurate estimates of winter wheat LNC, PNC, and NNI with the best VI combinations of Dualex, Multiplex, ASD, and RGB camera sensors, compared with GPR with full VIs or the MLR and PR methods.

Author Contributions: Conceptualization, X.S.; methodology, X.S. and D.Z.; investigation, G.Y. and X.X.; data curation, X.S., X.X. and H.F.; writing-original draft preparation, X.S. and D.Z.; writing-review and editing, C.Y. and G.Y. All authors have read and agreed to the published version of the manuscript.

Funding: This research was funded by the Key-Area Research and Development Program of Guangdong Province (2019B020214002), the National Key Technologies of Research and Development Program of China "Intergovernmental Cooperation in International Science and Technology Innovation" (2019YFE0125300), and the National Natural Science Foundation of China (41701375).

Institutional Review Board Statement: Not applicable.

Informed Consent Statement: Not applicable.

Data Availability Statement: The data are not publicly available due to the data also forms part of an ongoing study at this time.

Acknowledgments: We appreciate H. Chang and W.G. Li for their help during field data collection.

Conflicts of Interest: The authors declare no conflict of interest.

\section{References}

1. Mistele, B.; Schmidhalter, U. Estimating the nitrogen nutrition index using spectral canopy reflectance measurements. Eur. J. Agron. 2008, 29, 184-190. [CrossRef]

2. Ziadi, N.; Brassard, M.; Bélanger, G.; Claessens, A.; Tremblay, N.; Cambouris, A.N.; Nolin, M.C.; Parent, L.E. Chlorophyll measurements and nitrogen nutrition index for the evaluation of corn nitrogen status. Agron. J. 2008, 100, 1264-1273. [CrossRef]

3. Cao, Q.; Miao, Y.; Wang, H.; Huang, S.; Cheng, S.; Khosla, R.; Jiang, R. Nondestructive estimation of rice plant nitrogen status with Crop Circle multispectral active canopy sensor. Field Crops Res. 2013, 154, 133-144. [CrossRef]

4. Diacono, M.; Rubino, P.; Montemurro, F. Precision nitrogen management of wheat: A review. Agron. Sustain. Dev. 2013, 33, 219-241. [CrossRef]

5. Hansen, P.M.; Schjoerring, J.K. Reflectance measurement of canopy biomass and nitrogen status in wheat crops using normalized difference vegetation indices and partial least squares regression. Remote Sens. Environ. 2003, 86, S0034-S4257. [CrossRef]

6. Ecarnot, M.; Compan, F.; Roumet, P. Assessing leaf nitrogen content and leafmass per unit area of wheat in the field throughout plant cycle with a portable spectrometer. Field Crops Res. 2013, 140, 44-50. [CrossRef]

7. Debaeke, P.; Rouet, P.; Justes, E. Relationship between the normalized SPAD index and the nitrogen nutrition index: Application to durum wheat. J. Plant Nutr. 2006, 29, 75-92. [CrossRef]

8. Prost, L.; Jeuffroy, M.H. Replacing the nitrogen nutrition index by the chlorophyll meter to assess wheat N status. Agron. Sustain. Dev. 2007, 27, 321-330. [CrossRef]

9. Cao, Q.; Cui, Z.; Chen, X.; Khosla, R.; Dao, T.H.; Miao, Y. Quantifying spatial variability of indigenous nitrogen supply for precision nitrogen management in small scale farming. Precis. Agric. 2012, 13, 45-61. [CrossRef]

10. Tremblay, N.; Wang, Z.; Cerovic, Z.G. Sensing crop nitrogen status with fluorescence indicators-A review. Agron. Sust. Dev. 2012, 32, 451-464. [CrossRef]

11. Gabriel, J.L.; Zarco-Tejada, P.J.; López-Herrera, P.J.; Pérez-Martín, E.; Alonso-Ayuso, M.; Quemada, M. Airborne and ground level sensors for monitoring nitrogen status in a maize crop. Biosyst. Eng. 2017, 160, 124-133. [CrossRef]

12. Cerovic, Z.G.; Ounis, A.; Cartelat, A.; Latouche, G.; Goulas, Y.; Meyer, S. The use of chlorophyll fluorescence excitation spectra for the non-destructive in situ assessment of UV absorbing compounds in leaves. Plant Cell Environ. 2002, 25, 1663-1676. [CrossRef]

13. Cartelat, A.; Cerovic, Z.G.; Goulas, Y.; Meyer, S.; Lelarge, C.; Prioul, J.L. Optically assessed contents of leaf polyphenolics and chlorophyll as indicators of nitrogen deficiency in wheat (Triticum aestivum L.). Field Crops Res. 2005, 91, 35-49. [CrossRef]

14. Lamb, D.W.; Steyn-Ross, M.; Schaare, P.; Hanna, M.M. Estimating leaf nitrogen concentration in ryegrass (Lolium spp.) pasture using the chlorophyll rededge: Theoretical modeling and experimental observations. Int. J. Remote Sens. 2002, 23, 3619-3648. [CrossRef] 
15. Reyniers, M.; Vrindts, E. Measuring wheat nitrogen status from space and ground-based platform. Int. J. Remote Sens. 2006, 27, 549-567. [CrossRef]

16. Cho, M.A.; Skidmore, A.K. A new technique for extracting the red edge position from hyperspectral data: The linear extrapolation method. Remote Sens. Environ. 2006, 101, 181-193. [CrossRef]

17. Ben, G.N.; Cerovic, Z.G.; Germain, C.; Toutain, S.; Latouche, G. Non-destructive optical monitoring of grape maturation by proximal sensing. Sensors 2010, 10, 10040-10068. [CrossRef]

18. Mukhamediev, R.I.; Symagulov, A.; Kuchin, Y.; Zaitseva, E.; Bekbotayeva, A.; Yakunin, K.; Assanov, I.; Levashenko, V.; Popova, Y.; Akzhalova, A.; et al. Review of Some Applications of Unmanned Aerial Vehicles Technology in the Resource-Rich Country. Appl. Sci. 2021, 11, 10171. [CrossRef]

19. Shakhatreh, H.; Sawalmeh, A.H.; Al-Fuqaha, A.; Dou, Z.; Almaita, E.; Khalil, I.; Othman, N.S.; Khreishah, A.; Guizani, M. Unmanned aerial vehicles (UAVs): A survey on civil applications and key research challenges. IEEE Access 2019, 7, 48572-48634. [CrossRef]

20. Hu, H.; Zhang, J.; Sun, X.; Zhang, X. Estimation of leaf chlorophyll content of rice using image color analysis. Can. J. Remote Sens. 2013, 39, 185-190. [CrossRef]

21. Jia, B.; He, H.B.; Ma, F.Y.; Diao, M.; Jiang, G.Y.; Zheng, Z.; Cui, J.; Fan, H. Use of a digital camera to monitor the growth and nitrogen status of cotton. Sci. World J. 2014, 2014, 602647. [CrossRef]

22. Adamsen, F.G.; Pinter, J.P.; Barnes, M.E.; LaMorte, L.R.; Wall, W.G.; Leavitt, W.S. Measuring wheat senescence with a digital camera. Crop. Sci. 1999, 39, 719-724. [CrossRef]

23. Lukina, E.V.; Stone, M.L.; Raun, W.R. Estimating vegetation coverage in wheat using digital images. J. Plant Nutr. 1999, 22, 341-350. [CrossRef]

24. Elsayed, S.; Barmeier, G.; Schmidhalter, U. Passive Reflectance Sensing and Digital Image Analysis Allows for Assessing the Biomass and Nitrogen Status of Wheat in Early and Late Tillering Stages. Front. Plant. Sci. 2018, 9, 1478. [CrossRef]

25. Song, S.; Chong, H.; Chun, S.; Cheng, Y.; Dai, H. Research advancement on crop nitrogen nutrition diagnosis. Chin. J. Soil Sci. 2006, 37, 369-372, (In Chinese with English Abstract).

26. Guo, B.B.; Qi, S.L.; Heng, Y.R.; Duan, J.; Zhao, H.Y.; Zhang, Y.P.; Wu, W.F.; Xie, Y.X.; Zhu, Y.J. Remotely assessing leaf N uptake in winter wheat based on canopy hyperspectral red-edge absorption. Eur. J. Agron. 2017, 82, 113-124. [CrossRef]

27. Jacquemoud, S.; Baret, F. PROSPECT: A Model of Leaf Optical Properties Spectra. Remote Sens. Environ. 1990, 34, 75-91. [CrossRef]

28. Ollinger, S.V. Sources of variability in canopy reflectance and the convergent properties of plants. New Phytol. 2011, 189, 375-394. [CrossRef] [PubMed]

29. Verrelst, J.; Romijn, E.; Kooistra, L. Mapping vegetation density in aheterogeneous river floodplain ecosystem using pointable CHRIS/PROBA data. Remote Sens. 2012, 4, 2866-2889. [CrossRef]

30. Verrelst, J.; Camps-Valls, G.; Muñoz-Marí, J.; Rivera, J.P.; Veroustraete, F.; Clevers, J.G.P.W.; Moreno, J. Optical remote sensing and the retrieval of terrestrial vegetation bio-geophysical properties-A review. ISPRS J. Photogramm. Remote Sens. 2015, 108, 273-290. [CrossRef]

31. Clevers, J.G.P.W. Beyond NDVI: Extraction of biophysical variables from remote sensing imagery. In Land Use and Land Cover Mapping in Europe: Practices and Trends; Manakos, I., Braun, M., Eds.; Springer: Berlin/Heidelberg, Germany, 2014 ; pp. 363-381.

32. Glenn, E.P.; Huete, A.R.; Nagler, P.L.; Nelson, S.G. Relationship between remotely-sensed vegetation indices, canopy attributes and plant physiological processes: What vegetation indices can and cannot tell us about the landscape. Sensors 2008, 8, 2136-2160. [CrossRef] [PubMed]

33. Blum, A.; Langley, P. Selection of relevant features and examples in machine learning. Artif. Intell. 1997, 97, 245-271. [CrossRef]

34. Verrelst, J.; Rivera, J.P.; Gitelson, A.; Delegido, J.; Moreno, J.; Camps, V.G. Spectral band selection for vegetation properties retrieval using Gaussian processes regression. Int. J. Appl. Earth Observ. Geoinf. 2016, 52, 554-567. [CrossRef]

35. Miphokasap, P.; Honda, K.; Vaiphasa, C.; Souris, M.; Nagai, M. Estimating canopy nitrogen concentration in sugarcane using field imaging spectroscopy. Remote Sens. 2012, 4, 1651-1670. [CrossRef]

36. Verrelst, J.; Alonso, L.; Rivera Caicedo, J.; Moreno, J.; Camps-Valls, G. Gaussian process retrieval of chlorophyll content from imaging spectroscopy data. IEEE J. Sel. Top. Appl. Earth Observ. Remote Sens. 2013, 6, 867-874. [CrossRef]

37. Verrelst, J.; Alonso, L.; Camps-Valls, G.; Delegido, J.; Moreno, J. Retrieval of vegetation biophysical parameters using gaussian process techniques. IEEE Trans. Geosci. Remote Sens. 2012, 50, 1832-1843. [CrossRef]

38. Verrelst, J.; Malenovský, Z.; Van der Tol, C.; Camps-Valls, G.; Gastellu-Etchegorry, J.P.; Lewis, P.; North, P.; Moreno, J. Quantifying Vegetation Biophysical Variables from Imaging Spectroscopy Data: A Review on Retrieval Methods. Surv. Geophys. 2018, 40, 589-629. [CrossRef]

39. Rasmussen, C.E.; Williams, C.K.I. Gaussian Processes for Machine Learning; The MIT Press: Cambridge, MA, USA, 2006; pp. 7-30. Available online: http:/ / www.gaussianprocess.org/gpml/chapters/RW.pdf (accessed on 28 July 2021).

40. Li, F.; Miao, Y.; Hennig, S.D.; Gnyp, M.L.; Chen, X.; Jia, L. Evaluating hyperspectral vegetation indices for estimating nitrogen concentration of winter wheat at different growth stages. Precis. Agric. 2010, 11, 335-357. [CrossRef]

41. Ranjan, R.; Chopra, U.K.; Sahoo, R.N.; Singh, A.K.; Pradhan, S. Assessment of plant nitrogen stress in wheat (Triticum aestivum L.) through hyperspectral indices. Int. J. Remote Sens. 2012, 33, 6342-6360. [CrossRef]

42. Tian, Y.; Gu, K.; Chu, X.; Yao, X.; Cao, W.; Zhu, Y. Comparison of different hyperspectral vegetation indices for canopy leaf nitrogen concentration estimation in rice. Plant. Soil. 2013, 376, 193-209. [CrossRef] 
43. Song, X.; Feng, W.; He, L.; Xu, D.; Zhang, H.; Li, X.; Wang, Z.; Coburn, C.A.; Wang, C.; Guo, T. Examining view angle effects on leaf $\mathrm{N}$ estimation in wheat using field reflectance spectroscopy. ISPRS J. Photo. Remote Sens. 2016, 122, 57-67. [CrossRef]

44. Tian, Y.; Yao, X.; Yang, J.; Cao, W.; Hannaway, D.B.; Zhu, Y. Assessing newly developed and published vegetation indices for estimating rice leaf nitrogen concentration with ground-and space-based hyperspectral reflectance. Field Crops Res. 2011, 120, 299-310. [CrossRef]

45. Feng, W.; Yao, X.; Zhu, Y.; Tian, Y.C.; Cao, W.X. Monitoring leaf nitrogen status with hyperspectral reflectance in wheat. Eur. J. Agron. 2008, 28, 394-404. [CrossRef]

46. Daniela, S.; Mirco, B.; Pietroalessandro, B.; Stefano, B. Plant nitrogen concentration in paddy rice from field canopy hyperspectral radiometry. Field Crops Res. 2009, 111, 119-129. [CrossRef]

47. Wang, W.; Yao, X.; Tian, Y.; Liu, X.; Ni, J. Estimating leaf nitrogen concentration with three-band vegetation indices in rice and wheat. Field Crops Res. 2012, 129, 90-98. [CrossRef]

48. Rouse, J.W.; Haas, R.H.; Schell, J.A.; Deering, D.W.; Harlan, J.C. Monitoring the Vernal Advancement and Retrogradation of Natural Vegetation; NASA/GSFC, Type III, Final Report; NTRS: Greenbelt, MD, USA, 1973; pp. 7-15. Available online: https://ntrs.nasa. gov/archive/nasa/casi.ntrs.nasa.gov/19740004927.pdf (accessed on 26 July 2021).

49. Reujean, J.L.; Breon, F.M. Estimating PAR absorbed by vegetation from bidirectional reflectance measurements. Remote Sens Enviro. 1995, 51, 375-384. [CrossRef]

50. Gitelson, A.; Merzlyak, M.N. Spectral reflectance changes associated with autumn senescence of Aesculus hippocastanum L. and Acer platanoides L. leaves: Spectral features and relation to chlorophyll estimation. J. Plant Phys. 1994, 143, 286. [CrossRef]

51. Penuelas, J.; Filella, I.; Serrano, L.; Save, R. The reflectance at the 950-970 $\mathrm{nm}$ region as an indicator of plant water status. Int. J. Remote Sens. 1992, 14, 1887-1905. [CrossRef]

52. Gao, B.C. NDWI-A normalized difference water index for remote sensing of vegetation liquid water from space. Remote Sens. Environ. 1996, 58, 257-266. [CrossRef]

53. Hardisky, M.A.; Klemas, V.; Smart, R.M. The influence of Soil Salinity, Growth Form, and Leaf Moisture on the Spectral Radiance of Spartina alterniflora Canopies. Photo. Eng. Remote Sens. 1983, 48, 77-83.

54. Daughtry, C.S.T.; Walthall, C.L.; Kim, M.S.; de colstoun, E.B.; Mcmurtrey, J.E. Estimating corn leaf chlorophyll content from leaf and canopy reflectance. Remote Sens. Environ. 2000, 74, 229-239. [CrossRef]

55. Rondeaux, G.; Steven, M.; Baret, F. Optimization of soil-adjusted vegetation indices. Remote Sens. Environ. Feb. 1996, 55, 95-107. [CrossRef]

56. Qi, J.; Chehbouni, A.; Huete, A.R.; Kerr, Y.H. A Modified Soil Adjusted Vegetation Index (MSAVI). Remote Sens. Environ. 1994, 48, 119-126. [CrossRef]

57. Haboudane, D.; Miller, J.R.; Pattey, E.; Zarco-Tejada, P.J.; Strachan, I.B. Hyperspectral vegetation indices and novel algorithms for predicting green LAI of crop canopies: Modeling and validation in the context of precision agriculture. Remote Sens. Environ. 2004, 90, 337-352. [CrossRef]

58. Metternicht, G. Vegetation indices derived from high resolution airborne videography for precision crop management. Int. J. Rem. Sens. 2003, 24, 2855-2877. [CrossRef]

59. SpecTerra, S. Presentation and Analysis of Data; SpecTerra Services Pty Ltd.: Leederville, Australia, 1999; Available online: http:/ / www.specterra.com.au/dmsv_data_frame.html (accessed on 10 July 2021).

60. Demmig, A.B.; Adams, W.W. The role of xanthophylls cycle carotenoids in the protection of photosynthesis. Trends Plant. Sci. 1996, 1, 21-26. [CrossRef]

61. Dawson, T.P.; Curran, P.J.; Plummer, S.E. LIBERTY-Modeling the effects of leaf biochemical concentration on reflectance spectra. Remote Sens. Environ. 1998, 65, 50-60. [CrossRef]

62. Miller, J.; Hare, E.; Wu, J. Quantitative characterization of the vegetation red edge reflectance I. An inverted-Gaussian reflectance model. Int. J. Remote Sens. 1990, 11, 1755-1773. [CrossRef]

63. Yue, J.B.; Feng, H.K.; Jin, X.L.; Yuan, H.H.; Li, Z.H.; Zhou, C.Q.; Yang, G.J.; Tian, Q.J. A Comparison of Crop Parameters Estimation Using Images from UAV-Mounted Snapshot Hyperspectral Sensor and High-Definition Digital Camera. Remote Sens. 2018, 10, 1138. [CrossRef]

64. Woebbecke, D.; Meyer, G.; Von Bargen, K.; Mortensen, D. Color indices for weed identification under various soil, residue, and lighting conditions. Trans. ASAE 1995, 38, 259-269. [CrossRef]

65. Meyer, G.E.; Neto, J.C. Verification of color vegetation indices for automated crop imaging applications. Comput. Electron. Agric. 2008, 63, 282-293. [CrossRef]

66. Peñuelas, J.; Gamon, J.A.; Fredeen, A.L.; Merino, J.; Field, C.B. Reflectance indices associated with physiological changes in nitrogen- and water-limited sunflower leaves. Remote Sens. Environ. 1994, 48, 135-146. [CrossRef]

67. Bradstreet, R.B. The Kjeldahl Method for Organic Nitrogen; Academic Press Incorporated: New York, NY, USA, 1965.

68. Zhao, H.T.; Song, X.Y.; Yang, G.J.; Li, Z.H.; Zhang, D.Y.; Feng, H.K. Monitoring of Nitrogen and Grain Protein Content in Winter Wheat Based on Sentinel-2A Data. Remote Sens. 2019, 11, 1724. [CrossRef]

69. Lemaire, G.; Jeuffroy, M.H.; Gastal, F. Diagnosis tool for plant and crop N status in vegetative stage: Theory and practices for crop N management. Eur. J. Agron. 2008, 28, 614-624. [CrossRef]

70. Yue, S.; Meng, Q.; Zhao, R.; Li, F.; Chen, X.; Zhang, F.; Cui, Z. Critical nitrogen dilution curve for optimizing nitrogen management of winter wheat production in the North China Plain. Agron. J. 2012, 104, 523-529. [CrossRef] 
71. Willmott, C.J.; Matsuura, K. Advantages of the mean absolute error (MAE) over the root mean square error (RMSE) in assessing average model performance. Clim. Res. 2005, 30, 79-82. [CrossRef]

72. Schaeffer, D.L. A model evaluation methodology applicable to environmental assessment models. Ecol. Model. 1980, 8, 275-295. [CrossRef]

73. Nash, J.E.; Sutcliffe, J.V. River flow forecasting through conceptual models part I-A discussion of principles. J. Hydrol. 1970, 10, 282-290. [CrossRef]

74. Saberioon, M.; Amin, M.S.M.; Gholizadeh, A.; Ezri, M.H. A review of optical methods for assessing nitrogen contents during rice growth. Appl. Eng. Agric. 2014, 30, 657-669. [CrossRef]

75. Karim, S.T.; Cheng, T.; Liu, X.; Tian, Y.; Zhu, Y.; Cao, W.; Cao, Q. Potential of UAV-based active sensing for monitoring rice leaf nitrogen status. Front. Plant Sci. 2018, 9, 1834. [CrossRef]

76. Yang, G.; Liu, J.; Zhao, C.; Li, Z.; Huang, Y.; Yu, H. Unmanned aerial vehicle remote sensing for field-based crop phenotyping: Current status and perspectives. Front. Plant Sci. 2017, 8, 1111. [CrossRef] [PubMed]

77. Roberts, D.A.; Ustin, S.L.; Ogunjemiyo, S.; Greenberg, J.; Dobrowski, S.Z.; Chen, J.Q.; Hinckley, T.M. Spectral and structural measures of northwest forest vegetation at leaf to landscape scales. Ecosystems 2004, 7, 545-562. [CrossRef]

78. Jayme, G.A.B. Detection of nutrition deficiencies in plants using proximal images and machine learning: A review. Comput. Electron. Agric. 2019, 162, 482-492. [CrossRef] 